\title{
Risk of infections using anti-TNF agents in rheumatoid arthritis, psoriatic arthritis, and ankylosing spondylitis: a systematic review and meta-analysis.
}

\begin{abstract}
Introduction: Five anti-tumor necrosis factor (anti-TNF) agents have received regulatory approval for use in rheumatology: adalimumab, golimumab, infliximab, certolizumab, and etanercept. Apart from their well-documented therapeutic value, it is still uncertain to what extent they are associated with an increased risk of infectious adverse events.

Areas covered: We conducted a systematic review and meta-analysis of published randomized studies to determine the effect of anti-TNF drugs on the occurrence of infectious adverse events (serious infections; tuberculosis; opportunistic infections; any infection). We searched Medline, Embase, and the Cochrane Library up to May 2014 to identify eligible studies in adult patients with rheumatoid arthritis, psoriatic arthritis, or ankylosing spondylitis that evaluated anti-TNF drugs compared with placebo or no treatment.
\end{abstract}

Expert opinion: Our study encompassed data from 71 randomized controlled trials involving 22,760 participants (range of follow-up: 1 to 36 months) and seven open label extension studies with 2,236 participants (range of follow-up: 6 to 48 months). Quantitative synthesis of the available data found statistically significant increases in the occurrence of infections (20\%), serious infections (40\%), and tuberculosis (250\%) associated with anti-TNF drug use, while the data for opportunistic infections were scarce. The quality of synthesized evidence was judged as moderate. Further evidence from registries and long-term epidemiological studies are needed to better define the relationship between anti-TNF agents and infection complications.

Keywords: ankylosing spondylitis; anti-TNF drugs; drug safety; infections; meta-analysis; opportunistic infections; psoriatic arthritis; rheumatoid arthritis; serious infections; systematic review; tuberculosis. 


\section{Article highlights:}

- The association between anti-TNF drug use and infectious adverse events (AEs) is unclear.

- The authors conducted a systematic review and meta-analysis of published trials involving patients with rheumatoid arthritis, psoriatic arthritis, or ankylosing spondylitis to determine the effect of anti-TNF agents on the risk of infectious AEs (serious infections, tuberculosis, opportunistic infections, or any infection).

- $\quad 71$ RCTs with 22,760 patients, and seven OLE studies with 2,236 patients, met eligibility criteria and reported the occurrence of infectious AEs.

- Synthesis of the evidence supports the hypothesis that the use of anti-TNF drugs significantly increases the risk of infectious AEs. The meta-analysis showed an increase in the occurrence of infections (20\%), serious infections (40\%), and tuberculosis (250\%) associated with anti-TNF drug use, while the data for opportunistic infections were scarce.

- Given the increasing use of TNF inhibitors in adult patients with rheumatoid arthritis, psoriatic arthritis, and ankylosing spondylitis, it is important to continue monitoring their safety profiles through complementary sources (e.g., registries, and long-term epidemiological studies). 


\section{Introduction}

Five anti-tumor necrosis factor (anti-TNF) agents have received regulatory approval for clinical use in rheumatology: adalimumab, golimumab, infliximab, certolizumab, and etanercept. Adalimumab and golimumab are fully human monoclonal antibodies; infliximab is a chimeric monoclonal antibody with a murine variable region; certolizumab is a humanized Fab fragment conjugated to polyethylene glycol; and etanercept is a fusion protein of two TNFR2 receptor extracellular domains and the Fc fragment of human immunoglobulin $1[1]$.

Apart from their well-documented therapeutic value for several diseases including rheumatoid arthritis (RA), psoriatic arthritis (PsA), and ankylosing spondylitis (AS), it is still uncertain to what extent therapy with anti-TNF drugs may be associated with an increased risk of infectious adverse events (AEs). Post-marketing surveillance and observational studies provided the first indication that TNF inhibitors might be associated with an increased risk of serious infections [2,3]. Subsequently, a systematic review and meta-analysis of randomized controlled trials (RCTs), published in 2006, identified a statistically significant rise in the risk of infectious AEs in RA patients treated with infliximab and adalimumab (the odds ratio [OR] for serious infections was 2.0, with 95\% confidence interval [CI]: 1.3 to 3.1) [4]. However, observational studies have been inconsistent on this issue with reports of both increased risk [5-9] and of no increased risk [10-12].

Considering the conflicting results published in the literature, the high number of RCTs that have been performed since 2006, and the increasing use of TNF inhibitors as induction or maintenance treatment for adult patients with RA, PsA, or AS, we conducted a systematic review and meta-analysis of published trials to determine the occurrence of infectious AEs associated with use of anti-TNF agents. 


\section{Methods}

\subsection{Protocol and registration}

Our study protocol [13] is registered on PROSPERO, the international prospective register of systematic reviews. The current systematic review and meta-analysis was performed according to the PRISMA (Preferred Reporting Items for Systematic Reviews and Meta-analyses) statement [14].

\subsection{Data sources and search strategy}

A comprehensive search of MEDLINE and EMBASE bibliographic databases was conducted through May 2014. The following search terms were used: adalimumab, golimumab, infliximab, certolizumab pegol, etanercept, anti-tumo $(u) r$ necrosis factor(s), tumo $(u) r$ necrosis factor( $(s)$, tumo $(u) r$ necrosis factor alpha antibody(ies), tumo(u)r necrosis factor antibody(ies), anti-TNF, TNF, biologic(al) agent(s), or biologic(s), combined with rheumatoid arthritis, psoriatic arthritis, or ankylosing spondylitis. The search was limited to RCTs and humans. No language, date, or publication status restrictions were applied. We also searched the Cochrane Library for any RCT included in the Cochrane Central Register of Controlled Trials, and for any systematic review on the subject.

Results were exported and compiled into a common reference database using EndNote. References were then de-duplicated to derive a unique set of records. Two investigators independently examined the search results and screened the titles and abstracts to exclude clearly irrelevant reports. The full text of the selected articles was critically evaluated for eligibility, and their reference lists (and of relevant reviews and meta-analyses) were manually scanned to identify further eligible studies. Experts were consulted for additional evidence, but there was no search for unpublished studies or data.

\subsection{Study selection and data extraction}

We considered RCTs or open label extension (OLE) studies that evaluated an anti-TNF agent (adalimumab, certolizumab, etanercept, golimumab, or infliximab) as induction or maintenance therapy for adults with RA, PsA or AS, and reported the occurrence of infectious AEs. Eligible outcomes were: 
any infection, serious infections (infections that require antimicrobial therapy and/or hospitalization), tuberculosis, or opportunistic infections. We included studies that evaluated an anti-TNF therapy compared with placebo or no treatment, or multi-interventional therapies where the effect of anti-TNF treatment could be separated out (i.e. add-on to conventional disease-modifying anti-rheumatic drugs). In case of multiple publications from the same study, we selected the most updated one and extracted the data for the maximum follow-up time. OLE studies were eligible if they represented an extension of previous RCTs, and reported infectious AEs according to the group to which the patients were originally randomized.

Data extraction was undertaken by independent reviewers. Any discrepancy was resolved by consensus, referring back to the original article. The following data were extracted from each study: first author's last name, journal and year of publication, trial's acronym, study design and duration, number of participants, disease studied (RA, PsA, or AS), patient characteristics (age, concomitant treatments, duration of disease), intervention parameters (drug, dose, administration), and numbers of participants with events (serious infection; tuberculosis; opportunistic infection; or any infection) reported for the intervention and control groups.

\subsection{Assessment of risk of bias}

We evaluated the risk of bias $(\mathrm{RoB})$ in included studies using the Cochrane Collaboration's tool $[15,16]$, which addresses the following domains: sequence generation; allocation concealment; blinding; incomplete outcome data; and other sources of bias, such as extreme baseline imbalances in prognostic variables, selective crossover bias (i.e. subsequent anti-TNF treatment in the control groups), etc. These items were considered for the RoB assessment and were classified as "adequate" (low RoB), "inadequate" (high RoB), or "unclear". We considered only the information that was available in the full-text publications. Studies with adequate procedures in all domains were considered to have a low RoB; ones with inadequate procedures in one or more domains were considered to have a high RoB; and those with unclear procedures in one or more domains were considered to have unclear RoB. Discrepancies among reviewers were discussed, and agreement was reached by consensus.

On the other hand, OLE studies have higher RoB than the original trials. The study populations are no 
longer randomly allocated, they are not blinded, and usually represent only a proportion of the participants recruited in the original trial (e.g., those with an adequate drug response and tolerance during the original study period). Therefore, we decided a priori that the items related to sequence generation, allocation concealment, masking of participants, personnel and outcome assessors, and incomplete outcome data, should be rated as high RoB in the OLE study assessment.

\subsection{Data synthesis and analysis}

OR was the metric of choice in all comparisons. Study-level ORs and their 95\% CIs were calculated by reconstructing contingency tables based on the number of participants randomly assigned and the number of participants with the events of interest (analysis by intention to treat). When no events occurred in one group of the trial, we used a continuity correction that was inversely proportional to the relative size of the opposite group. In particular, the continuity correction for the treatment group was $1 /(\mathrm{R}+1)$, where $\mathrm{R}$ is the ratio of control group to treatment group sizes. Similarly, the continuity correction for the control group was $\mathrm{R} /(\mathrm{R}+1)$. This methodological approach outperforms the use of a constant continuity correction of 0.5 in a setting of sparse data and imbalanced study groups [17]. Trials reporting zero-event data for both study groups were excluded from the analysis.

We used two techniques to calculate the pooled effect estimates: the fixed-effects model (MantelHaenszel approach [18]) and the random-effects model (DerSimonian \& Laird approach [19]). In the absence of heterogeneity, the fixed- and the random-effects model provide similar results. When heterogeneity is found, the random-effects model might be more prudent, though both techniques may be biased.

After the overall meta-analysis, we conducted subgroup analyses by the anti-TNF drug (adalimumab, golimumab, infliximab, certolizumab, or etanercept) to investigate potentially different effects on risk. To assess any association between dose of TNF inhibitors and risk of infectious AEs, we also conducted a sensitivity analysis using (from the multi-arm trials) only the data referring to the intervention arms exposed to the highest doses. When no events were reported, the highest dose arm was merged with the second, the third highest, etc., in order to produce a group with at least one event, and include the study in the particular analysis. Full data were used from the two-arm trials. 
Finally, we performed meta-regression analyses to investigate the impact of certain trial characteristics on the effect estimates. We converted all ORs by logarithmic transformation to achieve more symmetrical distributions. The natural logarithm of the OR was the dependent variable, and (i) age of participants enrolled and (ii) duration of follow-up were entered as covariates. This analysis was an indirect way to deal with aspects such as the possibility of effect modification by age, and to examine for increasing or decreasing risks with increasing duration of drug use, a feature associated with causal relationships. We applied a weighted regression model, so that the more precise studies have more influence in the analysis.

Regarding the open-label extension studies, their usefulness for generating reliable and valid data has been repeatedly challenged in the literature [20,21]. To avoid any biased or spuriously precise results, we did not include OLEs in our primary meta-analyses but synthesized their data separately.

Selective outcome reporting or publication bias was assessed using the funnel plot, Begg's test [22], and Egger's test [23]. The between-study heterogeneity was evaluated using Cochran's Q test [24] with a 0.10 level of significance. We also calculated the I-squared statistic [25], which describes the percentage variation across studies that is due to heterogeneity rather than chance. Negative values of I-squared were put equal to zero, so that I-squared lies between $0 \%$ and $100 \%$. An I-squared value less than $40 \%$ was considered as indicative of "not important heterogeneity" and a value over $75 \%$ as indicative of “considerable heterogeneity" [26].

The quality of the meta-analytic evidence for each of the outcomes was assessed using GRADE (Grading of Recommendations Assessment, Development and Evaluation) [27].

For all statistical analyses, we used Stata 11 software (Stata Corp., College Station, Texas, USA), and the R software environment [28], version 3.1.1, and the "meta" package for R [29], version 3.8-0. All p-values are two-tailed. For all tests (except for heterogeneity), a p-value less than 0.05 was regarded as statistically significant.

\subsection{Role of the funding source}

This study was supported by an unrestricted grant from Pfizer Italia. The funding source had no role in the design and conduct of the study; collection, management, analysis, or interpretation of the data; 
preparation, review, or approval of the manuscript; and decision to submit it for publication. 


\section{Results}

\subsection{Search results}

A summary of the evidence search and selection process is shown in Figure 1, and in the Appendix. Seventy-one RCTs [30-100] met the eligibility criteria and reported the occurrence of infectious AEs (serious infection, tuberculosis, opportunistic infection, or any infection) during the study period; we were thus able to conduct a post hoc analysis of these trials, calculate ORs for the outcomes of interest according to the intention-to-treat principle, and incorporate them in the meta-analyses.

These 71 RCTs evaluated infliximab $(n=16)$, adalimumab $(n=22)$, golimumab $(n=11)$, certolizumab pegol $(n=7)$, or etanercept $(n=15)$ as induction or maintenance treatments for adult patients with RA $(n=46)$, PsA $(n=9)$, or AS $(n=16)$. A total of 22,760 individuals participated in these trials; 14,766 in treatment groups, and 7,994 in control groups.

Substantial imbalance was observed between the treatment and control group sizes within studies (median ratio, 2:1; maximum ratio, 7:1). The mean age of participants ranged from 30 to 62 years, and follow-up times from 1 to 36 months, between studies. A total experience of approximately 15,100 person-years was reached ( 8 months per patient, on average). The publication dates of these trials ranged from 1999 to 2014. A summary of the trials' characteristics is given in Table 1.

Though most of the OLE studies were excluded because they did not report infectious AEs per study arm, we identified seven eligible OLEs [42,56,101-105] involving 2,236 participants. Their follow-up times ranged from 6 to 48 months. The outcomes of interest were reported according to the group to which patients were originally randomized, so we could calculate ORs and synthesize the evidence.

\subsection{Risk of bias in the studies included in meta-analysis}

Random sequence generation: 11 of 71 RCTs (15.5\%) reported adequate methods for sequence generation and were judged to be at low RoB. Information in 60 trials (84.5\%) was insufficient to permit judgement (i.e. unclear RoB). 
Allocation concealment: 33 of 71 RCTs (46.5\%) reported adequate methods for allocation concealment (low RoB). In 38 trials (53.5\%) information was insufficient (unclear RoB).

Blinding of participants and personnel: 20 of 71 RCTs (28.2\%) were double-blind, three were not (4.2\%), while for the other 48 trials (67.6\%) information was insufficient.

Blinding of outcome assessment: In 26 of 71 RCTs (36.6\%) the outcome assessment was blind, one was not blind (1.4\%), while for the other 44 trials $(62.0 \%)$ information was insufficient.

Incomplete outcome data: 49 of 71 RCTs (69.0\%) were judged to be at high RoB. Fifteen trials (21.1\%) were judged to be at low RoB, while for seven (9.9\%) information was insufficient.

Other sources of bias: Nine studies (12.7\%) suffered selective crossover across groups (high RoB).

Overall, the assessment indicated high RoB across 51 of the 71 included RCTs (71.8\%) and unclear RoB for 19 RCTs (26.8\%). Quality assessment items are presented in Figure 2. Regarding the OLE studies' assessment, all studies were rated as high RoB.

\subsection{Results of meta-analyses}

\subsubsection{Serious infections}

Fifty-eight $\quad$ RCTs $\quad[30-32,34-38,40-49,51-58,60-76,78,79,81,82,84-89,91,94,95,99,100] \quad$ involving 20,796 adult patients with RA, PsA, or AS, evaluated anti-TNF drugs and reported the occurrence of serious infections (2.6\% in treatment groups; and 2.0\% in control groups). Exposure to anti-TNF agents was associated with increased risk of serious infectious AEs, under both a fixed-effects model (OR: 1.41, 95\% CI: 1.16, 1.73) and a random-effects model (OR: 1.25, 95\% CI: 1.01, 1.55) (Table 2). The ORs with their 95\% CIs for the individual trials, and the pooled results are presented in a forest plot (Figure 3).

Cochran's Q test had a p-value of 0.78 and the corresponding I-squared statistic was $0 \%$, both indicating very little variability between studies. In contrast, the $p$-values for the Begg's test $(p=0.06)$ and the Egger's test $(\mathrm{p}=0.09)$ suggested a possible bias. Indeed, there was a funnel plot asymmetry, with the left corner of the pyramidal part of the funnel missing (Figure 4A). Small studies reporting relative risks lower than the unity are probably missing, and thus the estimated pooled OR for serious infections may have been overestimated. 
The subgroup analysis investigating potentially different effects on risk by the anti-TNF drugs (adalimumab, golimumab, infliximab, certolizumab, or etanercept; Figure 3) was statistically significant under the fixed-effects model $(\mathrm{p}=0.05)$, while it was not under the random-effects model ( $\mathrm{p}=0.14$ ), suggesting that etanercept and golimumab might have a better safety profile for serious infections, with point effects estimates closer to 1.0 (Figure 3).

To assess any association between higher doses of TNF inhibitors and risk of serious infections, we conducted a sensitivity analysis. The results did not materially change (fixed-effects, OR: $1.46,95 \% \mathrm{CI}$ : 1.19, 1.79; random-effects, OR: 1.36, 95\% CI: 1.09, 1.69) (Table 2).

Meta-regression analysis, using the age of participants and the duration of follow-up as covariates, did not reveal any significant association (univariate analysis: age, $\mathrm{p}=0.72$; duration of follow-up, $\mathrm{p}=0.21$; and in multivariate analysis: age, $\mathrm{p}=0.69$; duration of follow-up, $\mathrm{p}=0.20$ ).

The quantitative synthesis of six open-label extension phases of RCTs [42,56,101,103-105] did not provide any further evidence for the association between anti-TNF drugs and serious infections. The calculated summary effect estimate was not statistically significant assuming either a fixed-effects model (OR: 1.33, 95\% CI: 0.77, 2.29) or a random-effects model (OR: 1.19, 95\% CI: 0.68, 2.07). We found no evidence of selective outcome reporting or publication bias, or heterogeneity among the OLE studies (Table 2).

\subsubsection{Tuberculosis}

Nineteen RCTs $[33,43,46,48,51,52,54,57,59,62,67,73,75,81,84,93,94,99,100]$ involving 8,320 adults with RA, PsA, or AS, evaluated anti-TNF drugs and reported the occurrence of tuberculosis; it was $0.6 \%$ in the treatment groups (5,339 patients; 32 events), while no event was reported in the control groups (2,981 patients). Thus, continuity corrections (inversely proportional to the relative size of the opposite arm) were used in the analysis. Exposure to anti-TNF agents was associated with a statistically significant 3-fold increase in the risk of tuberculosis (fixed-effects model, OR: 3.53, 95\% CI: 1.58, 7.85; random-effects model, OR: 3.29, 95\% CI: 1.48, 7.33) (Table 2). The ORs with their 95\% CIs from the individual trials, and the pooled results, are presented in Figure 5. We found suggestive evidence of 
selective outcome reporting or publication bias, but no heterogeneity among studies (Table 2).

The subgroup analysis by the type of anti-TNF drug (Figure 5) did not reveal any difference among the drug-specific effect estimates (tests for subgroup differences: fixed effects, $\mathrm{p}=0.98$; random effects, $\mathrm{p}=0.99$ ). However, the power of this analysis is typically low, and, therefore, we cannot exclude clinically important differences between anti-TNF drugs treatment and progression of tuberculosis.

In the sensitivity analysis conducted to assess any association between higher doses of TNF inhibitors and risk of tuberculosis, the results did not materially change (fixed-effects, OR: $3.32,95 \%$ CI: 1.54 , 7.15; random-effects, OR: 3.23, 95\% CI: 1.50, 6.98) (Table 2).

Meta-regression analysis, using the age of participants and the duration of follow-up as covariates, did not reveal any association (univariate analysis: age, $\mathrm{p}=0.89$; duration of follow-up, $\mathrm{p}=0.98$; and in multivariate analysis: age, $\mathrm{p}=0.87$; duration of follow-up, $\mathrm{p}=0.93$ ).

\subsubsection{Opportunistic infections}

Only six RCTs [35,43,63,66,73,84] involving 3,886 adult patients reported the occurrence of opportunistic infections ( $0.3 \%$ in treatment groups; $0.3 \%$ in control groups). The association between anti-TNF drug use and the risk of opportunistic infections was neutral (fixed-effects, OR: 0.94, 95\% CI: 0.33, 2.64; random-effects model, OR: $0.81,95 \%$ CI: $0.23,2.87$ ). The ORs with their $95 \%$ CIs from the individual trials, and the pooled results, are presented in Figure 6. We found no evidence of heterogeneity among the studies, selective outcome reporting or publication bias (Table 2).

The subgroup analysis, investigating potentially different effects on risk between types of anti-TNF drugs, did not reveal any difference among the drug-specific effect estimates. However, the power of this analysis was considerably low. Moreover, the sensitivity analysis did not suggest association between higher doses of the anti-TNF drugs and the risk of developing opportunistic infections (Table 2).

\subsubsection{Any infection}

In this analysis, 37 trials $\quad[31,32,34-37,39,42-45,47,50-53,55-57,60,62,64,65,67-$ 69,71,72,74,79,84,87,92,93,97-99] involving 12,796 adult patients with RA, PsA, or AS, were 
incorporated. They examined anti-TNF agents and reported "the number of patients with at least one infection during the study" (frequency was $30.8 \%$ for the treatment groups, and $28.5 \%$ for control groups). Exposure to TNF inhibitors was associated with increased risk of any infectious AE (fixedeffects, OR: 1.20, 95\% CI: 1.10, 1.30; random-effects, OR: 1.20, 95\% CI: 1.06, 1.36) (Table 2). The ORs with their 95\% CIs from the primary studies, and the pooled results, are shown in Figure 7.

The Cochran's Q test had a p-value lower than 0.01 and the corresponding I-squared was $46 \%$, both indicating important heterogeneity between studies. In contrast, the funnel plot (Figure 4B), along with Begg's test $(\mathrm{p}=0.95)$ and Egger's test $(\mathrm{p}=0.75)$, showed no evidence of selective outcome reporting or publication bias.

The subgroup analysis by the type of anti-TNF drugs (Figure 7) did not reveal a significant difference among the drug-specific effect estimates (tests for subgroup differences: fixed effects, $\mathrm{p}=0.78$; random effects, $\mathrm{p}=0.76$ ).

The sensitivity analysis performed to assess any association between higher doses of TNF inhibitors and risk of any infection, confirmed the results reported above (fixed-effects, OR: 1.21, 95\% CI: 1.11, 1.32; random-effects, OR: 1.22, 95\% CI: 1.07, 1.39) (Table 2).

Importantly, in the meta-regression analysis, we obtained an estimate that was statistically significantly different from zero for the regression coefficient of the duration of follow-up (months) (coefficient $=0.023 ; \mathrm{se}=0.011 ; \mathrm{p}=0.037 ;$ Figure 8). The between-trial heterogeneity was reduced by $17 \%$ when duration of follow-up was included as an explanatory variable in the model. The results did not substantially change when we included both the age of participants $(\mathrm{p}=0.88)$ and duration of follow-up (coefficient $=0.023 ; \mathrm{se}=0.011 ; \mathrm{p}=0.039$ ) in the model. This finding suggests that treatment with anti-TNF agents is associated with an increasing risk of infectious AEs, as duration of follow-up increases.

Synthesis of six OLE studies [42,56,101-104] with longer follow-up periods (range: 6 to 48 months) provided further evidence for the association between anti-TNF drug use and risk of any infectious AEs (fixed-effects, OR: 1.69, 95\% CI: 1.31, 2.18; random-effects, OR: 1.56, 95\% CI: 1.05, 2.33) (Table 2). We found no evidence of heterogeneity among the OLEs, selective outcome reporting, or publication bias (Table 2). 


\subsection{Quality of the evidence}

In this meta-analysis, the quality of synthesized evidence is rated as "moderate" for the following reasons: (i) the evidence was derived from RCTs (randomized study design is considered the gold standard for assessing drugs); (ii) the meta-analytic effect estimates are precise (except for opportunistic infections); (iii) the results are consistent (heterogeneity was low or moderate across studies); and (iv) the vast majority of the RCTs included in our study are characterized by high or unclear RoB, as assessed with the Cochrane Collaboration's tool (a fact that downgrades the quality of evidence). A moderate quality of evidence means that we are moderately confident in the effect estimate. The true effect is likely to be close to the estimate of the effect, but there is a possibility that it is substantially different. 


\section{Conclusion}

This systematic review encompassed data from 71 published RCTs involving 22,760 adult patients with rheumatologic disease (range of follow-up: 1 to 36 months), and from seven OLE studies with 2,236 patients (range of follow-up: 6 to 48 months). Quantitative synthesis of the available evidence supports the hypothesis that the use of anti-TNF drugs significantly affects the risk of infectious AEs. In particular, we found an increase in the occurrence of infections (20\%), serious infections (40\%), and tuberculosis $(250 \%)$ associated with anti-TNF drug use, while the data for the opportunistic infections were scarce. Using the GRADE system [28], a summary of findings and strength of evidence is shown in Table 3.

Over the last years, use of anti-TNF drugs by rheumatologic patients has been constantly increasing, and evidence on their safety continues to be collected [106]. Given the uncertainty on the effect of these agents on the risk of infectious AEs, we undertook a systematic review and meta-analysis on the topic. Seventy-one RCTs with 22,760 adult patients met the eligibility criteria and reported the occurrence of infectious AEs, as a secondary (safety) endpoint. Study-level relative risk estimates were calculated, in accordance with the intention-to-treat principle, and were appropriately synthesized. Our results provide relevant evidence that the use of anti-TNF drugs significantly affects the risk of infectious AEs. Similar results were noted when we analyzed for higher drug doses or synthesized the seven eligible OLE studies. Thus, the findings of the present meta-analysis are in line with several observational studies reporting a significant rise in the risk of infectious AEs associated with anti-TNF drug use [5-9].

In 2006, Bongartz et al. published the first meta-analysis on this topic [4]. They identified a two-fold increase in the risk of serious infections associated with anti-TNF drugs (OR: 2.0, 95\% CI: 1.3, 3.1), and an even higher increase when the analysis was restricted to high-dose groups vs. placebo (OR: 2.3, 95\% CI: $1.5,3.6)$. Since then, several meta-analyses have been published with conflicting results. Leombruno et al. [107] analyzed 18 RCTs involving over 8,800 RA patients treated over an average of 0.8 years. They did not identify an increased risk of serious infections (OR: 1.21, 95\% CI: 0.89, 1.63). However, high-dose therapy was associated with a two-fold increase in the risk of serious infections. In 2010, Bernatsky et al. [108] published a meta-analysis of seven observational studies involving RA 
patients. Anti-TNF therapy appeared to significantly increase the risk of serious infections (OR: 1.37, 95\% CI: 1.18, 1.60). In 2011, Thompson et al. [109] conducted a meta-analysis of six RCTs and showed no increased risk of serious infection in patients with early RA receiving anti-TNF therapy (OR: 1.28, 95\% CI: $0.82,2.00)$. As compared to those studies, our meta-analysis uses a much broader evidence base, includes a large number of trials $(n=71)$, and provides updated evidence that can be appropriately integrated into relevant clinical guidelines.

This study has some limitations. Firstly, our search was restricted to published studies and we did not search for unpublished/original data. Secondly, the trials included in our review are characterized by high or unclear RoB, as assessed with the Cochrane Collaboration's tool. This is of concern, because the quality of the meta-analysis depends on the quality of the primary studies; if they are biased, then the meta-analysis will be biased as well. However some studies were rated at low risk of bias, and the estimates from studies at low risk did not differ from studies at high risk of bias. This increases the overall confidence we have in the final estimates. Thirdly, because duration of follow-up was up to 36 months, risk estimates resulting from longer exposure to anti-TNF agents are not possible. Given the meta-regression finding that anti-TNF drug therapy is associated with higher risks of infectious AEs as duration of follow-up increases, evidence describing infection risk during longer durations of anti-TNF therapy is required. However, the present study also has merits. It was conducted using a rigorous and extensive bibliographic search that allowed the inclusion of all relevant published RCTs. Furthermore, the relatively precise meta-analytic effect estimates, the absence of significant between-study heterogeneity, and the stability of the results in the subgroup and sensitivity analyses, strengthen our confidence in the accuracy of our findings.

\section{Expert opinion}

The results of our meta-analyses raise concerns about the use of anti-TNF in patients with infectious diseases. Included trials carefully excluded patients with histories of infections such as latent tuberculosis. Even after careful selection of patients for inclusion, our meta-analysis provides definitive evidence that anti-TNF drugs can disturb physiological cytokine-mediated signaling. The tuberculosis meta-analysis is paradigmatic. All events were in the anti-TNF arms, while the control arms were 
tuberculosis free. There are several prospective and retrospective studies exploring the association between anti-TNFs and tuberculosis [110-115]. The annual incidence rate varied depending on the country observed and the anti-TNF drug administered. Therefore, it is important to establish accurate latent tuberculosis infection screening strategy before commencing anti-TNF therapy in patients with immune-mediated inflammatory diseases [116]. The implementation of recommendations for latent tuberculosis infection screening and (prophylactic) treatment before initiation of anti-TNF therapy might reduce the infection incidence. Risk stratification scores associated with host demographic and clinical features, and previous or current non-biologic therapies are warranted to support the decision to start a treatment and the safest biologic choice [117]. For all anti-TNF drugs, the tuberculosis incidence rate was consistently higher than that in the general population, but infliximab and adalimumab were associated with the highest incidence rates when compared to etanercept [118]. Despite all anti-TNF neutralize TNF resulting in disruption of the granuloma that normally compartmentalizes Mycobacterium tuberculosis, etanercept might have a different impact on immunity that may allow the granuloma to reconstitute itself, thus preventing bacillary dissemination [119]. Our review did not identify substantial differences among the anti-TNFs drugs. However, the power of these subgroup analyses is typically limited: up to two cases of tuberculosis were included in trials exploring etanercept and golimumab, an inadequate number to demonstrate a definite association between the use of the drug and reactivation tuberculosis. Additionally concomitant corticosteroid and methotrexate therapies might be important confounding factors, hiding differences on drug inflammatory mechanisms and safety profile.

Given the increased risk of reoccurrence of infections, rheumatologists should further consider that the number of patients experiencing these adverse events is higher in studies other then RCTs such that the clinical consequences of the treatment might be more severe. There is not clear hypothesis for assuming that harms are different in directions or magnitude of effects across diseases, so we did not group studies by disease. We hypothesized that there were not strong differences in the case mix of patients across populations included in the RCTs, so harms, overall, should have been fairly consistent across studies. However there was some heterogeneity, so some differences between patient populations cannot be excluded. 
In conclusion, synthesis of existing evidence from RCTs involving rheumatologic patients confirms that anti-TNF drug use significantly increases the risk of infectious AEs, especially the risk for serious infections and tuberculosis. Given the increasing use of anti-TNF agents in adult patients with RA, PsA, or AS, it is important to continue monitoring their safety profiles, through complementary sources of research data, such as registries and long-term epidemiological studies. 


\section{Acknowledgements}

We are grateful to Dr Antonio Spadaro who participated in the early phase of this study. Unfortunately, he passed away before seeing the completion of the review.

\section{Declaration of interest}

This study was supported by an unrestricted grant from Pfizer Italia through a service agreement with Health Publishing \& Services Srl. Health Publishing \& Services Srl supports research activities at the IRCCS Galeazzi Orthopedic Institute and the IRCCS Mario Negri Institute for Pharmacological Research. Valentina Marino is an employee of Pfizer Italia. All the other authors declare no conflict of interest related to the article. 


\section{References}

[1] Thalayasingam N, Isaacs J. Anti-TNF therapy. Best Pract Res Clin Rheumatol 2011;25:549-67

[2] Gomez-Reino JJ, Carmona L, Valverde VR, et al. Treatment of rheumatoid arthritis with tumor necrosis factor inhibitors may predispose to significant increase in tuberculosis risk: a multicenter active surveillance report. Arthritis Rheum 2003;48:2122-7

[3] Wallis RS, Broder MS, Wong JY, et al. Granulomatous infectious diseases associated with tumor necrosis factor antagonists. Clin Infect Dis 2004;38:1261-5

[4] Bongartz T, Sutton AJ, Sweeting MJ, et al. Anti-TNF antibody therapy in rheumatoid arthritis and the risk of serious infections and malignancies: systematic review and meta-analysis of rare harmful effects in randomized controlled trials. JAMA 2006;295:2275-85** First published meta-analysis on the topic. It demonstrated a $100 \%$ increase in the risk of serious infections among anti-TNF drug users.

[5] Curtis JR, Patkar N, Xie A, et al. Risk of serious bacterial infections among rheumatoid arthritis patients exposed to tumor necrosis factor alpha antagonists. Arthritis Rheum 2007;56:1125-33

[6] Bernatsky S, Hudson M, Suissa S. Anti-rheumatic drug use and risk of serious infections in rheumatoid arthritis. Rheumatology 2007;46:1157-60

[7] Salliot C, Gossec L, Ruyssen-Witrand A, et al. Infections during tumour necrosis factor-alpha blocker therapy for rheumatic diseases in daily practice: a systematic retrospective study of 709 patients. Rheumatology 2007;46:327-34

[8] Listing J, Strangfeld A, Kary S, et al. Infections in patients with rheumatoid arthritis treated with biologic agents. Arthritis Rheum 2005;52:3403-12

[9] Carmona L, Descalzo MA, Perez-Pampin E, et al. All-cause and cause-specific mortality in rheumatoid arthritis are not greater than expected when treated with tumour necrosis factor antagonists. Ann Rheum Dis 2007;66:880-5 
[10] Wolfe F, Caplan L, Michaud K. Treatment for rheumatoid arthritis and the risk of hospitalization for pneumonia: associations with prednisone, disease-modifying anti-rheumatic drugs, and anti-tumor necrosis factor therapy. Arthritis Rheum 2006;54:628-34

[11] Schneeweiss S, Setoguchi S, Weinblatt ME, et al. Anti-tumor necrosis factor alpha therapy and the risk of serious bacterial infections in elderly patients with rheumatoid arthritis. Arthritis Rheum 2007;56:1754-64

[12] Dixon WG, Watson K, Lunt M, et al. Rates of serious infection, including site-specific and bacterial intracellular infection, in rheumatoid arthritis patients receiving anti-tumor necrosis factor therapy: results from the British Society for Rheumatology Biologics Register. Arthritis Rheum 2006;54:2368-76

[13] Risk of infections using anti-TNF agents in rheumatoid arthritis, psoriatic arthritis and ankylosing spondylitis: a systematic review and meta-analysis. PROSPERO 2014:CRD42014009993. Available at: http://www.crd.york.ac.uk/PROSPERO/display record.asp?ID=CRD42014009993 [Last accessed 7 February 2016]

[14] Moher D, Liberati A, Tetzlaff J, et al. Preferred reporting items for systematic reviews and meta-analyses: the PRISMA statement. Ann Intern Med 2009;151:264-9, W64

[15] Higgins JP, Altman DG, Gøtzsche PC, et al. The Cochrane Collaboration's tool for assessing risk of bias in randomised trials. BMJ 2011;343:d5928

[16] Bonovas S, Lytras T, Nikolopoulos G. On the criteria used for assessing the risk of bias in randomized trials included in systematic reviews and meta-analyses addressing adverse effects. Eur J Epidemiol 2015;30:249-50

[17] Sweeting MJ, Sutton AJ, Lambert PC. What to add to nothing? Use and avoidance of continuity corrections in meta-analysis of sparse data. Stat Med 2004;23:1351-75

[18] Mantel N, Haenszel W. Statistical aspects of the analysis of data from retrospective studies of disease. J Natl Cancer Inst 1959;22:719-48

[19] DerSimonian R, Laird N. Meta-analysis in clinical trials. Control Clin Trials 1986;7:177-88 
[20] Cho MK. Open-label extension studies: are they really research? Am J Bioeth 2014;14:60-1

[21] Day RO, Williams KM. Open-label extension studies: do they provide meaningful information on the safety of new drugs? Drug Saf 2007;30:93-105

[22] Begg CB, Mazumdar M. Operating characteristics of a rank correlation test for publication bias. Biometrics 1994;50:1088-101

[23] Egger M, Davey Smith G, Schneider M, Minder C. Bias in meta-analysis detected by a simple, graphical test. BMJ 1997;315:629-34

[24] Cochran WG. The combination of estimates from different experiments. Biometrics $1954 ; 810: 101-29$

[25] Higgins JP, Thompson SG, Deeks JJ, Altman DG. Measuring inconsistency in meta-analyses. BMJ 2003;327:557-60

[26] Higgins JPT, Green S, editors. Cochrane Handbook for Systematic Reviews of Interventions. The Cochrane Collaboration; 2011, version 5.0.1

[27] Guyatt GH, Oxman AD, Vist GE, et al. GRADE: an emerging consensus on rating quality of evidence and strength of recommendations. BMJ 2008;336:924-6

[28] R Development Core Team. R: A Language and Environment for Statistical Computing. Vienna, Austria: R Foundation for Statistical Computing; 2014. Available at: http://www.Rproject.org/ [Last accessed 7 Feb 2016]

[29] Schwarzer G. meta: An R package for meta-analysis. R News 2007;7:40-5

[30] Smolen JS, Nash P, Durez P, et al. Maintenance, reduction, or withdrawal of etanercept after treatment with etanercept and methotrexate in patients with moderate rheumatoid arthritis (PRESERVE): a randomised controlled trial. Lancet 2013;381:918-29

[31] Landewé R, Braun J, Deodhar A, et al. Efficacy of certolizumab pegol on signs and symptoms of axial spondyloarthritis including ankylosing spondylitis: 24-week results of a double-blind randomised placebo-controlled Phase 3 study. Ann Rheum Dis 2014;73:39-47 
[32] Mease PJ, Fleischmann R, Deodhar AA, et al. Effect of certolizumab pegol on signs and symptoms in patients with psoriatic arthritis: 24-week results of a Phase 3 double-blind randomised placebo-controlled study (RAPID-PsA). Ann Rheum Dis 2014;73:48-55

[33] Sieper J, Lenaerts J, Wollenhaupt J, et al. Efficacy and safety of infliximab plus naproxen versus naproxen alone in patients with early, active axial spondyloarthritis: results from the double-blind, placebo-controlled INFAST study, Part 1. Ann Rheum Dis 2014;73:101-7

[34] Huang F, Gu J, Zhu P, et al. Efficacy and safety of adalimumab in Chinese adults with active ankylosing spondylitis: results of a randomised, controlled trial. Ann Rheum Dis 2014;73:58794

[35] Takeuchi T, Yamanaka H, Ishiguro N, et al. Adalimumab, a human anti-TNF monoclonal antibody, outcome study for the prevention of joint damage in Japanese patients with early rheumatoid arthritis: the HOPEFUL 1 study. Ann Rheum Dis 2014;73:536-43

[36] Takeuchi T, Harigai M, Tanaka Y, et al. Golimumab monotherapy in Japanese patients with active rheumatoid arthritis despite prior treatment with disease-modifying antirheumatic drugs: results of the phase $2 / 3$, multicentre, randomised, double-blind, placebo-controlled GO-MONO study through 24 weeks. Ann Rheum Dis 2013;72:1488-95

[37] Weinblatt ME, Fleischmann R, Huizinga TW, et al. Efficacy and safety of certolizumab pegol in a broad population of patients with active rheumatoid arthritis: results from the REALISTIC phase IIIb study. Rheumatology (Oxford) 2012;51:2204-14

[38] van Vollenhoven RF, Fleischmann R, Cohen S, et al. Tofacitinib or adalimumab versus placebo in rheumatoid arthritis. N Engl J Med 2012;367:508-19

[39] Sieper J, van der Heijde D, Dougados M, et al. Efficacy and safety of adalimumab in patients with non-radiographic axial spondyloarthritis: results of a randomised placebo-controlled trial (ABILITY-1). Ann Rheum Dis 2013;72:815-22

[40] Leirisalo-Repo M, Kautiainen H, Laasonen L, et al. Infliximab for 6 months added on combination therapy in early rheumatoid arthritis: 2-year results from an investigator-initiated, 
randomised, double-blind, placebo-controlled study (the NEO-RACo Study). Ann Rheum Dis $2013 ; 72: 851-7$

[41] Detert J, Bastian H, Listing J, et al. Induction therapy with adalimumab plus methotrexate for 24 weeks followed by methotrexate monotherapy up to week 48 versus methotrexate therapy alone for DMARD-naive patients with early rheumatoid arthritis: HIT HARD, an investigatorinitiated study. Ann Rheum Dis 2013;72:844-50

[42] Weinblatt ME, Bingham CO 3rd, Mendelsohn AM, et al. Intravenous golimumab is effective in patients with active rheumatoid arthritis despite methotrexate therapy with responses as early as week 2: results of the phase 3, randomised, multicentre, double-blind, placebo-controlled GOFURTHER trial. Ann Rheum Dis 2013;72:381-9

[43] Kavanaugh A, Fleischmann RM, Emery P, et al. Clinical, functional and radiographic consequences of achieving stable low disease activity and remission with adalimumab plus methotrexate or methotrexate alone in early rheumatoid arthritis: 26-week results from the randomised, controlled OPTIMA study. Ann Rheum Dis 2013;72:64-71

[44] Choy E, McKenna F, Vencovsky J, et al. Certolizumab pegol plus MTX administered every 4 weeks is effective in patients with RA who are partial responders to MTX. Rheumatology (Oxford) 2012;51:1226-34

[45] Tanaka Y, Harigai M, Takeuchi T, et al. Golimumab in combination with methotrexate in Japanese patients with active rheumatoid arthritis: results of the GO-FORTH study. Ann Rheum Dis $2012 ; 71: 817-24$

[46] Baranauskaite A, Raffayová H, Kungurov NV, et al. Infliximab plus methotrexate is superior to methotrexate alone in the treatment of psoriatic arthritis in methotrexate-naive patients: the RESPOND study. Ann Rheum Dis 2012;71:541-8

[47] Fleischmann R, Cutolo M, Genovese MC, et al. Phase lib dose-ranging study of the oral JAK inhibitor tofacitinib (CP-690,550) or adalimumab monotherapy versus placebo in patients with active rheumatoid arthritis with an inadequate response to disease-modifying anti-rheumatic drugs. Arthritis Rheum 2012;64:617-29 
[48] van Vollenhoven RF, Kinnman N, Vincent E, et al J. Atacicept in patients with rheumatoid arthritis and an inadequate response to methotrexate: results of a phase II, randomized, placebocontrolled trial. Arthritis Rheum 2011;63:1782-92

[49] Barkham N, Coates LC, Keen H, et al. Double-blind placebo-controlled trial of etanercept in the prevention of work disability in ankylosing spondylitis. Ann Rheum Dis 2010;69:1926-8

[50] Dougados M, Combe B, Braun J, et al. A randomised, multicentre, double-blind, placebocontrolled trial of etanercept in adults with refractory heel enthesitis in spondyloarthritis: the HEEL trial. Ann Rheum Dis 2010;69:1430-5.

[51] Kremer J, Ritchlin C, Mendelsohn A, et al. Golimumab, a new human anti-tumor necrosis factor alpha antibody, administered intravenously in patients with active rheumatoid arthritis: Fortyeight-week efficacy and safety results of a phase III randomized, double-blind, placebocontrolled study. Arthritis Rheum 2010;62:917-28

[52] Emery P, Fleischmann RM, Moreland LW, et al. Golimumab, a human anti-tumor necrosis factor alpha monoclonal antibody, injected subcutaneously every four weeks in methotrexatenaive patients with active rheumatoid arthritis: twenty-four-week results of a phase III, multicenter, randomized, double-blind, placebo-controlled study of golimumab before methotrexate as first-line therapy for early-onset rheumatoid arthritis. Arthritis Rheum $2009 ; 60: 2272-83$

[53] Smolen JS, Kay J, Doyle MK, et al. Golimumab in patients with active rheumatoid arthritis after treatment with tumour necrosis factor alpha inhibitors (GO-AFTER study): a multicentre, randomised, double-blind, placebo-controlled, phase III trial. Lancet 2009;374:210-21

[54] Chen DY, Chou SJ, Hsieh TY, et al. Randomized, double-blind, placebo-controlled, comparative study of human anti-TNF antibody adalimumab in combination with methotrexate and methotrexate alone in Taiwanese patients with active rheumatoid arthritis. J Formos Med Assoc 2009;108:310-9

[55] Kavanaugh A, McInnes I, Mease P, et al. Golimumab, a new human tumor necrosis factor alpha antibody, administered every four weeks as a subcutaneous injection in psoriatic arthritis: 
Twenty-four-week efficacy and safety results of a randomized, placebo-controlled study. Arthritis Rheum 2009;60:976-86

[56] Keystone EC, Genovese MC, Klareskog L, et al. Golimumab, a human antibody to tumour necrosis factor $\{$ alpha\} given by monthly subcutaneous injections, in active rheumatoid arthritis despite methotrexate therapy: the GO-FORWARD Study. Ann Rheum Dis 2009;68:789-96

[57] Smolen J, Landewé RB, Mease P, et al. Efficacy and safety of certolizumab pegol plus methotrexate in active rheumatoid arthritis: the RAPID 2 study. A randomised controlled trial. Ann Rheum Dis 2009;68:797-804

[58] Fleischmann R, Vencovsky J, van Vollenhoven RF, et al. Efficacy and safety of certolizumab pegol monotherapy every 4 weeks in patients with rheumatoid arthritis failing previous diseasemodifying antirheumatic therapy: the FAST4WARD study. Ann Rheum Dis 2009;68:805-11

[59] Keystone E, Heijde Dv, Mason D Jr, et al. Certolizumab pegol plus methotrexate is significantly more effective than placebo plus methotrexate in active rheumatoid arthritis: findings of a fiftytwo-week, phase III, multicenter, randomized, double-blind, placebo-controlled, parallel-group study. Arthritis Rheum 2008;58:3319-29

[60] Inman RD, Davis JC Jr, Heijde Dv, et al. Efficacy and safety of golimumab in patients with ankylosing spondylitis: results of a randomized, double-blind, placebo-controlled, phase III trial. Arthritis Rheum 2008;58:3402-12

[61] Bejarano V, Quinn M, Conaghan PG, et al. Effect of the early use of the anti-tumor necrosis factor adalimumab on the prevention of job loss in patients with early rheumatoid arthritis. Arthritis Rheum 2008;59:1467-74

[62] Combe B, Codreanu C, Fiocco U, et al. Efficacy, safety and patient-reported outcomes of combination etanercept and sulfasalazine versus etanercept alone in patients with rheumatoid arthritis: a double-blind randomised 2-year study. Ann Rheum Dis 2009;68:1146-52

[63] Emery P, Breedveld FC, Hall S, et al. Comparison of methotrexate monotherapy with a combination of methotrexate and etanercept in active, early, moderate to severe rheumatoid 
arthritis (COMET): a randomised, double-blind, parallel treatment trial. Lancet 2008;372:37582

[64] Kay J, Matteson EL, Dasgupta B, et al. Golimumab in patients with active rheumatoid arthritis despite treatment with methotrexate: a randomized, double-blind, placebo-controlled, doseranging study. Arthritis Rheum 2008;58:964-75

[65] Miyasaka N; CHANGE Study Investigators. Clinical investigation in highly disease-affected rheumatoid arthritis patients in Japan with adalimumab applying standard and general evaluation: the CHANGE study. Mod Rheumatol 2008;18:252-62

[66] Schiff M, Keiserman M, Codding C, et al. Efficacy and safety of abatacept or infliximab vs placebo in ATTEST: a phase III, multi-centre, randomised, double-blind, placebo-controlled study in patients with rheumatoid arthritis and an inadequate response to methotrexate. Ann Rheum Dis 2008;67:1096-103

[67] van der Heijde D, Klareskog L, Landewé R, et al. Disease remission and sustained halting of radiographic progression with combination etanercept and methotrexate in patients with rheumatoid arthritis. Arthritis Rheum 2007;56:3928-3

[68] Weisman MH, Paulus HE, Burch FX, et al. A placebo-controlled, randomized, double-blinded study evaluating the safety of etanercept in patients with rheumatoid arthritis and concomitant comorbid diseases. Rheumatology (Oxford) 2007;46:1122-5

[69] Genovese MC, Mease PJ, Thomson GT, et al. Safety and efficacy of adalimumab in treatment of patients with psoriatic arthritis who had failed disease modifying antirheumatic drug therapy. J Rheumatol 2007;34:1040-50

[70] Zhou H, Jang H, Fleischmann RM, et al. Pharmacokinetics and safety of golimumab, a fully human anti-TNF-alpha monoclonal antibody, in subjects with rheumatoid arthritis. J Clin Pharmacol 2007;47:383-96

[71] van der Heijde D, Da Silva JC, Dougados M, et al. Etanercept $50 \mathrm{mg}$ once weekly is as effective as $25 \mathrm{mg}$ twice weekly in patients with ankylosing spondylitis. Ann Rheum Dis 2006;65:1572-7 
[72] van der Heijde D, Kivitz A, Schiff MH, et al. Efficacy and safety of adalimumab in patients with ankylosing spondylitis: results of a multicenter, randomized, double-blind, placebocontrolled trial. Arthritis Rheum 2006;54:2136-46

[73] Westhovens R, Yocum D, Han J, et al. The safety of infliximab, combined with background reatments, among patients with rheumatoid arthritis and various comorbidities: a large, randomized, placebo-controlled trial. Arthritis Rheum 2006;54:1075-86

[74] Abe T, Takeuchi T, Miyasaka N, et al. A multicenter, double-blind, randomized, placebo controlled trial of infliximab combined with low dose methotrexate in Japanese patients with rheumatoid arthritis. J Rheumatol 2006;33:37-44

[75] Breedveld FC, Weisman MH, Kavanaugh AF, et al. The PREMIER study: A multicenter, randomized, double-blind clinical trial of combination therapy with adalimumab plus methotrexate versus methotrexate alone or adalimumab alone in patients with early, aggressive rheumatoid arthritis who had not had previous methotrexate treatment. Arthritis Rheum 2006;54:26-37

[76] Mease PJ, Gladman DD, Ritchlin CT, et al. Adalimumab for the treatment of patients with moderately to severely active psoriatic arthritis: results of a double-blind, randomized, placebocontrolled trial. Arthritis Rheum 2005;52:3279-89

[77] Marzo-Ortega H, McGonagle D, Jarrett S, et al. Infliximab in combination with methotrexate in active ankylosing spondylitis: a clinical and imaging study. Ann Rheum Dis 2005;64:1568-75

[78] Antoni CE, Kavanaugh A, Kirkham B, et al. Sustained benefits of infliximab therapy for dermatologic and articular manifestations of psoriatic arthritis: results from the infliximab multinational psoriatic arthritis controlled trial (IMPACT). Arthritis Rheum 2005;52:1227-36

[79] van der Heijde D, Dijkmans B, Geusens P, et al. Efficacy and safety of infliximab in patients with ankylosing spondylitis: results of a randomized, placebo-controlled trial (ASSERT). Arthritis Rheum 2005;52:582-91

[80] Antoni C, Krueger GG, de Vlam K, et al. Infliximab improves signs and symptoms of psoriatic arthritis: results of the IMPACT 2 trial. Ann Rheum Dis 2005;64:1150-7 
[81] St Clair EW, van der Heijde DM, Smolen JS, et al. Combination of infliximab and methotrexate therapy for early rheumatoid arthritis: a randomized, controlled trial. Arthritis Rheum 2004;50:3432-43

[82] Mease PJ, Kivitz AJ, Burch FX, et al. Etanercept treatment of psoriatic arthritis: safety, efficacy, and effect on disease progression. Arthritis Rheum 2004;50:2264-72

[83] Rau R, Simianer S, van Riel PL, et al. Rapid alleviation of signs and symptoms of rheumatoid arthritis with intravenous or subcutaneous administration of adalimumab in combination with methotrexate. Scand J Rheumatol 2004;33:145-53

[84] Keystone EC, Kavanaugh AF, Sharp JT, et al. Radiographic, clinical, and functional outcomes of treatment with adalimumab (a human anti-tumor necrosis factor monoclonal antibody) in patients with active rheumatoid arthritis receiving concomitant methotrexate therapy: a randomized, placebo-controlled, 52-week trial. Arthritis Rheum 2004;50:1400-11

[85] van de Putte LB, Atkins C, Malaise M, et al. Efficacy and safety of adalimumab as monotherapy in patients with rheumatoid arthritis for whom previous disease modifying antirheumatic drug treatment has failed. Ann Rheum Dis 2004;63:508-16

[86] Keystone EC, Schiff MH, Kremer JM, et al. Once-weekly administration of $50 \mathrm{mg}$ etanercept in patients with active rheumatoid arthritis: results of a multicenter, randomized, double-blind, placebo-controlled trial. Arthritis Rheum 2004;50:353-63

[87] Furst DE, Schiff MH, Fleischmann RM, et al. Adalimumab, a fully human anti tumor necrosis factor-alpha monoclonal antibody, and concomitant standard antirheumatic therapy for the treatment of rheumatoid arthritis: results of STAR (Safety Trial of Adalimumab in Rheumatoid Arthritis). J Rheumatol 2003;30:2563-71

[88] van de Putte LB, Rau R, Breedveld FC, et al. Efficacy and safety of the fully human anti-tumour necrosis factor alpha monoclonal antibody adalimumab (D2E7) in DMARD refractory patients with rheumatoid arthritis: a 12 week, phase II study. Ann Rheum Dis 2003;62:1168-77 
[89] Davis JC Jr, Van Der Heijde D, Braun J, et al. Recombinant human tumor necrosis factor receptor (etanercept) for treating ankylosing spondylitis: a randomized, controlled trial. Arthritis Rheum 2003;48:3230-6

[90] Brandt J, Khariouzov A, Listing J, et al. Six-month results of a double-blind, placebo-controlled trial of etanercept treatment in patients with active ankylosing spondylitis. Arthritis Rheum 2003;48:1667-75

[91] Weinblatt ME, Keystone EC, Furst DE, et al. Adalimumab, a fully human anti-tumor necrosis factor alpha monoclonal antibody, for the treatment of rheumatoid arthritis in patients taking concomitant methotrexate: the ARMADA trial. Arthritis Rheum 2003;48:35-45

[92] Gorman JD, Sack KE, Davis JC Jr. Treatment of ankylosing spondylitis by inhibition of tumor necrosis factor alpha. N Engl J Med 2002;346:1349-56

[93] Braun J, Brandt J, Listing J, et al. Treatment of active ankylosing spondylitis with infliximab: a randomised controlled multicentre trial. Lancet 2002;359:1187-93

[94] Van Den Bosch F, Kruithof E, Baeten D, et al. Randomized double-blind comparison of chimeric monoclonal antibody to tumor necrosis factor alpha (infliximab) versus placebo in active spondylarthropathy. Arthritis Rheum 2002;46:755-65

[95] Lipsky PE, van der Heijde DM, St Clair EW, et al. Infliximab and methotrexate in the treatment of rheumatoid arthritis. Anti-Tumor Necrosis Factor Trial in Rheumatoid Arthritis with Concomitant Therapy Study Group. N Engl J Med 2000;343:1594-602

[96] Mease PJ, Goffe BS, Metz J, et al. Etanercept in the treatment of psoriatic arthritis and psoriasis: a randomised trial. Lancet 2000;356:385-90

[97] Kavanaugh A, St Clair EW, McCune WJ, et al. Chimeric anti-tumor necrosis factor-alpha monoclonal antibody treatment of patients with rheumatoid arthritis receiving methotrexate therapy. J Rheumatol 2000;27:841-50

[98] Weinblatt ME, Kremer JM, Bankhurst AD, et al. A trial of etanercept, a recombinant tumor necrosis factor receptor: Fc fusion protein, in patients with rheumatoid arthritis receiving methotrexate. N Engl J Med 1999;34:253-9 
[99] Kim HY, Lee SK, Song YW, et al. A randomized, double-blind, placebo-controlled, phase III study of the human anti-tumor necrosis factor antibody adalimumab administered as subcutaneous injections in Korean rheumatoid arthritis patients treated with methotrexate. APLAR Journal of Rheumatology 2007;10: 9-16

[100] Zhang FC, Hou Y, Huang F, et al. Infliximab versus placebo in rheumatoid arthritis patients receiving concomitant methotrexate: A preliminary study from China. APLAR Journal of Rheumatology 2006;9:127-30

[101] Kavanaugh A, Mease P. Treatment of psoriatic arthritis with tumor necrosis factor inhibitors: longer-term outcomes including enthesitis and dactylitis with golimumab treatment in the longterm extension of a randomized, placebo-controlled study (GO-REVEAL). J Rheumatol Suppl 2012;89:90-3

[102] Dougados M, Braun J, Szanto S, et al. Continuous efficacy of etanercept in severe and advanced ankylosing spondylitis: results from a 12-week open-label extension of the SPINE study. Rheumatology (Oxford) 2012;51:1687-96

[103] Braun J, Deodhar A, Dijkmans B, et al. Efficacy and safety of infliximab in patients with ankylosing spondylitis over a two-year period. Arthritis Rheum 2008;59:1270-8

[104] van der Heijde D, Burmester G, Melo-Gomes J, et al. The safety and efficacy of adding etanercept to methotrexate or methotrexate to etanercept in moderately active rheumatoid arthritis patients previously treated with monotherapy. Ann Rheum Dis 2008;67:182-8

[105] Maini RN, Breedveld FC, Kalden JR, et al. Therapeutic efficacy of multiple intravenous infusions of anti-tumor necrosis factor alpha monoclonal antibody combined with low-dose weekly methotrexate in rheumatoid arthritis. Arthritis Rheum 1998;41:1552-63

[106] Ding T, Ledingham J, Luqmani R, et al. BSR and BHPR rheumatoid arthritis guidelines on safety of anti-TNF therapies. Rheumatology (Oxford) 2010;49:2217-9 ** Detailed rheumatoid arthritis guidelines on the safety of anti-TNF therapies. 
[107] Leombruno JP, Einarson TR, Keystone EC. The safety of anti-tumour necrosis factor treatments in rheumatoid arthritis: meta and exposure-adjusted pooled analyses of serious adverse events. Ann Rheum Dis 2009;68:1136-45 * Recent meta-analysis on the topic.

[108] Bernatsky S, Habel Y, Rahme E. Observational studies of infections in rheumatoid arthritis: a meta-analysis of tumor necrosis factor antagonists. J Rheumatol 2010;37:928-31 *Recent metaanalysis of observational studies on the topic.

[109] Thompson AE, Rieder SW, Pope JE. Tumor necrosis factor therapy and the risk of serious infection and malignancy in patients with early rheumatoid arthritis: a meta-analysis of randomized controlled trials. Arthritis Rheum 2011;63:1479-85*Recent meta-analysis of observational studies on the topic.

[110] Cantini F, Niccoli L, Goletti D. Adalimumab, etanercept, infliximab, and the risk of tuberculosis: data from clinical trials, national registries, and postmarketing surveillance. J Rheumatol Suppl 2014;91:47-55

[111] van Dartel SA, Fransen J, Kievit W, et al. Difference in the risk of serious infections in patients with rheumatoid arthritis treated with adalimumab, infliximab and etanercept: results from the Dutch Rheumatoid Arthritis Monitoring (DREAM) registry. Ann Rheum Dis 2013;72:895-900

[112] Atzeni F, Sarzi-Puttini P, Botsios C, et al. Long-term anti-TNF therapy and the risk of serious infections in a cohort of patients with rheumatoid arthritis: comparison of adalimumab, etanercept and infliximab in the GISEA registry. Autoimmun Rev 2012;12:225-9

[113] Salmon-Ceron D, Tubach F, Lortholary O, et al. Drug-specific risk of non-tuberculosis opportunistic infections in patients receiving anti-TNF therapy reported to the 3-year prospective French RATIO registry. Ann Rheum Dis 2011;70:616-23

[114] Dixon WG, Hyrich KL, Watson KD, et al. Drug-specific risk of tuberculosis in patients with rheumatoid arthritis treated with anti-TNF therapy: results from the British Society for Rheumatology Biologics Register. Ann Rheum Dis 2010;69:522-8

[115] Tubach F, Salmon D, Ravaud P, et al. Risk of tuberculosis is higher with anti-tumor necrosis factor monoclonal antibody therapy than with soluble tumor necrosis factor receptor therapy: 
The three-year prospective French Research Axed on Tolerance of Biotherapies registry. Arthritis Rheum 2009;60:1884-94

[116] Goletti D, Sanduzzi A, Delogu G. Performance of the tuberculin skin test and interferon- $\gamma$ release assays: an update on the accuracy, cutoff stratification, and new potential immune-based approaches. J Rheumatol Suppl. 2014;91:24-31

[117] Cantini F, Nannini C, Niccoli L, et al. Guidance for the management of patients with latent tuberculosis infection requiring biologic therapy in rheumatology and dermatology clinical practice. Autoimmun Rev. 2015;14(6):503-509

[118] Xie X, Li F, Chen JW, Wang J. Risk of tuberculosis infection in anti-TNF- $\alpha$ biological therapy: from bench to bedside. J Microbiol Immunol Infect. 2014;47(4):268-74

[119] Keane J. TNF-blocking agents and tuberculosis: new drugs illuminate an old topic. Rheumatology (Oxford). 2005;44(6):714-20. 


\section{Legends for Figures}

Figure 1. Summary of evidence search and selection (flow iagram).

Abbreviations. RCTs: randomized controlled trials; OLEs: open label extension studies; AEs: adverse events.

Figure 2. Risk-of-bias assessments for the randomized trials included in the meta-analysis. Symbols. green (+): low risk of bias; yellow (?): unclear risk of bias; red (-): high risk of bias.

Figure 3. Forest plot for serious infections: results from individual studies and meta-analyses. Abbreviations. OR: odds ratio; CI: confidence interval.

Figure 4A. Contour-enhanced funnel plot for serious infections.

Footnote. Ideally, the funnel plot should have a symmetrical shape with a wide base and a narrow peak. The figure indicates that smaller trials reporting odds ratios lower than the unity are probably missing, and thus the pooled effect estimate for serious infections may have been overestimated. Tests of publication bias: Begg's $\mathrm{p}=0.07$; Egger's $\mathrm{p}=0.09$.

Figure 4B. Contour-enhanced funnel plot for any infection.

Footnote. Tests of publication bias: Begg's p=0.95; Egger's p $=0.75$.

Figure 5. Forest plot for tuberculosis: results from individual studies and meta-analyses.

Abbreviations. OR: odds ratio; CI: confidence interval.

Figure 6. Forest plot for opportunistic infections: results from individual studies and meta-analyses.

Abbreviations. OR: odds ratio; CI: confidence interval. 
Figure 7. Forest plot for any infection: results from individual studies and meta-analyses. Abbreviations. OR: odds ratio; CI: confidence interval.

Figure 8. Log odds ratios of any infection as a function of the duration of follow-up. The greater the variance of a study, the smaller the area of the circle and the less that observation contributes to the overall effect. The superimposed line is obtained by meta-regression analysis. 
Figure 1
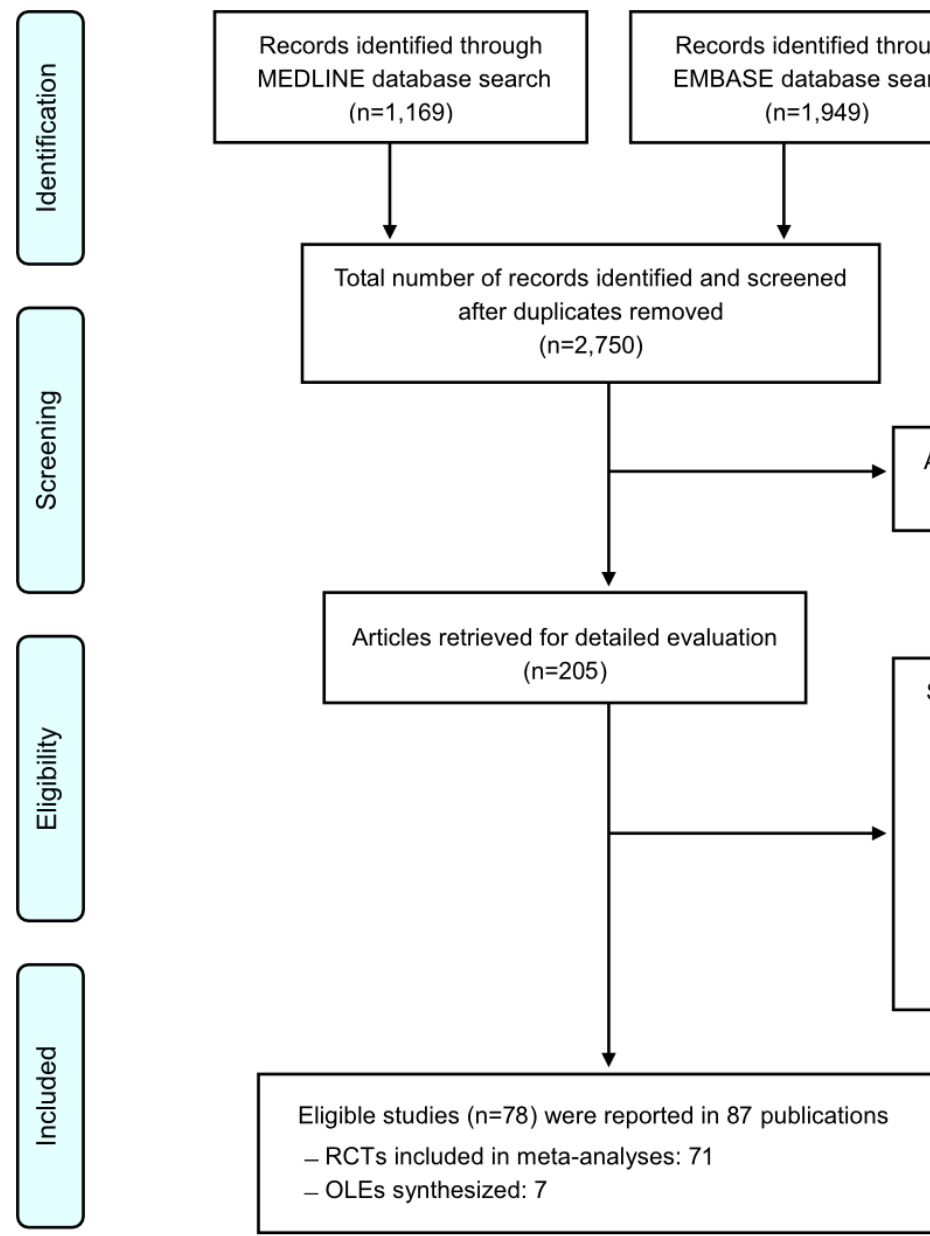

Articles excluded based on title/abstract $(n=2,545)$

Studies excluded $(n=118)$

- Review articles: 30

- Not RCTs or OLEs: 6

- Not in a population with the disease of interest: 5

- Not appropriate control group: 15

- Not in adults: 8

- Secondary analyses: 5

- Studies not reporting the occurrence of infectious AEs: 22

- OLEs not reporting infectious AEs per study arm: 27 


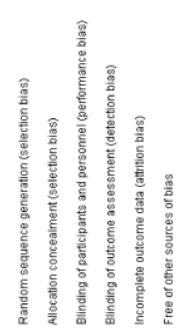

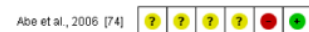

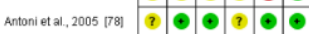

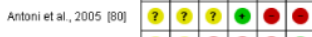
$2012[46]$ 3 $3 \bullet \odot \odot$

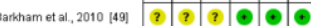

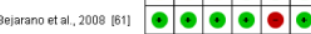

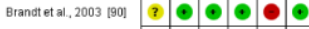
Braun et al, 2002 [93] $\odot \odot \bullet$ ? 3 ?

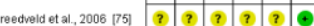

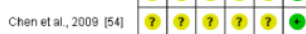

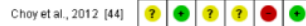
combe et al, 2009 [62] 3 ? 3 - 3 ? $\begin{array}{ccccccc}\text { Daris et al, } 2003 \text { [89] } & 3 & 3 & 3 & \bullet & \bullet & \bullet\end{array}$

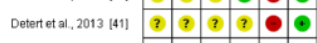
$\begin{array}{lllllll}\text { Dougados et al. } 2010 \text { 150] } & 3 & 3 & \text { ? } & \text { ? } & - & -\end{array}$

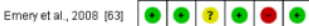

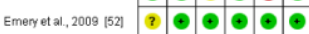

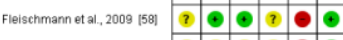
Fleischmann et al. 2012 [47] 3 ? ? ? ? \begin{tabular}{lllllll}
\hline Furstet al. 2003 [87] & 3 & 3 & 3 & 3 & 0 & $\bullet$
\end{tabular}

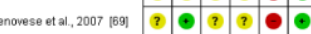
Gorman et al, $2002[92]$ ๑

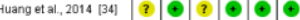
Inmanet al, 2008 [60] 3 ? $\bullet \bullet$ Kavanaugh et al, 2000 [97]

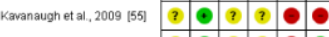
Kavanaugh et al a, 2013 [43] 3 ? \begin{tabular}{ll|lllll} 
Kay et al, 2008 [64] & 3 & 3 & 3 & 3 & $\bullet$ & $\bullet$
\end{tabular}

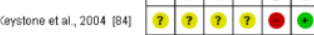

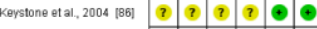

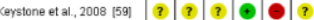
kesstone et al 2009 [56] \begin{tabular}{ll|lllll} 
Kim et al., 2007 [99] & 3 & 3 & 3 & 3 & $\bullet$ & $\bullet$
\end{tabular} Kremer et al. 2010 [51] 3 - $-\bullet$ ?

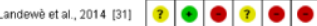

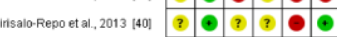

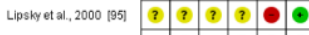

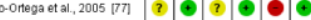

Mease et al, 2000 [196] $\odot$ ? $\odot$ ?

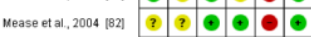

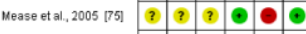
Mease et al 2014 [32] ? $\odot \bullet$ ?

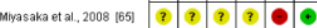

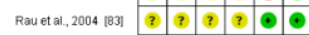

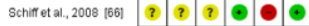
Slieper et al, 2013 [39] 3 -

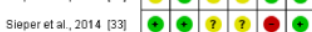

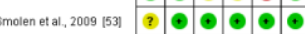
Smolen et al. 2009 [57] 3 ? 3 ? 3 ? Smolen et at, 2013 [30] $\odot \bullet \bullet-\odot \bullet$

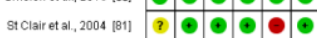

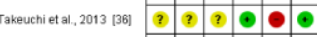
$\begin{array}{lllllll}\text { Takeuchi et al, } 2014[\text { [35] } & 3 & 3 & 3 & 3 & \bullet & -\end{array}$

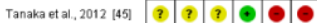

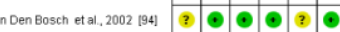

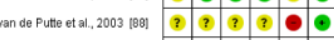
van de Puthe et al, 2004 [85] $-\odot$ -

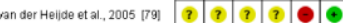

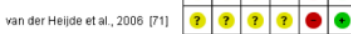

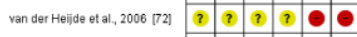
van der Heijde et al, 2007 [67] 3 ? 3 van Yollenhoven et al, 2011 [48!

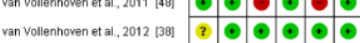

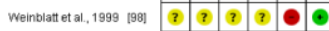
$\begin{array}{llllllll}\text { Weinblat et al, } 2003 \text { [91] } & 3 & 3 & 3 & 3 & 3 & -\end{array}$

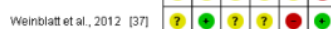

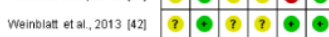
\begin{tabular}{lllllllll} 
Weisman et al, 2007 [68] & 3 & 3 & 3 & 3 & $?$ & $\odot$ \\
\hline
\end{tabular}

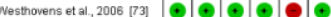

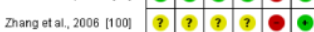

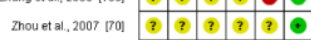

Figure 2 
Figure 3

Randomized Controlled Trials
Adalimumab
Bejarano et al., 2008 [61]
Breedveld et al., 2006 [75]
Chen et al., 2009 [54]
Detert et al., 2013 [41]
Fleischmann et al., 2012 [47]
Furst et al., 2003 [87]
Genovese et al., 2007 [69]
Huang et al., 2014 [34]
Kavanaugh et al., 2013 [43]
Keystone et al., 2004 [84]
Kim et al., 2007 [99]
Mease et al., 2005 [76]
Miyasaka et al., 2008 [65]
Takeuchi et al., 2014 [35]
van de Putte et al., 2003 [88]
van de Putte et al., 2004 [85]
van der Heijde et al., 2006 [72]
van Vollenhoven et al., 2011 [48]
van Vollenhoven et al., 2012 [38]
Weinblatt et al.,, 2003 [91]
Fixed effect model
Random effects model

reatment Control $\begin{array}{llll}3 & 75 & 2 & 73\end{array}$ $\begin{array}{lrrr}9 & 268 & 7 & 257\end{array}$ $\begin{array}{lll}35 & 0 & 12\end{array}$ $\begin{array}{lll}87 & 4 & 85 \\ 53 & 1 & 59\end{array}$ $\begin{array}{llll}4 & 318 & 6 & 318\end{array}$ $\begin{array}{lrrr}4 & 51 & 1 & 49\end{array}$ $\begin{array}{llll}6 & 419 & 1 & 200\end{array}$ $\begin{array}{rrrr}2 & 65 & 0 & 63 \\ 1 & 151 & 2 & 162\end{array}$ $\begin{array}{llll}13 & 265 & 1 & 87\end{array}$ $\begin{array}{llll}2 & 171 & 1 & 163\end{array}$ $\begin{array}{lllr}4 & 214 & 0 & 70\end{array}$ $\begin{array}{llll}0 & 434 & 0 & 110\end{array}$ $\begin{array}{rrrr}0 & 208 & 1 & 107 \\ 3 & 79 & 1 & 76\end{array}$ $\begin{array}{lrrr}3 & 79 & 1 & 76 \\ 0 & 204 & 1 & 108\end{array}$ $\begin{array}{rrrr}0 & 204 & 1 & 108 \\ 2 & 209 & 0 & 62\end{array}$ $4050 \quad 2693$

\section{Certolizumab}

Choy et al., 2012 [44] Fleischmann et al., 2009 [58] andewè et al., 2014 [31] Mease et al., 2014 [32] Smolen et al., 2009 [57] Weinblatt et al., 2012 [37] Fixed effect model Random effects model

\section{Etanercep}

Barkham et al., 2010 [49] Combe et al., 2009 [62]

Davis et al., 2003 [89]

Emery et al., 2008 [63]

Keystone et al., 2004 [86]

Mease et al., 2004 [82]

Smolen et al., 2013 [30]

van der Heijde et al., 2006 [71]
van der Heijde et al., 2007 [67]

Weisman et al., 2007 [68]

Fixed effect mode

Random effects model

$\begin{array}{llll}11 & 126 & 9 & 121\end{array}$

$2 \begin{array}{llll}111 & 0 & 109\end{array}$

$\begin{array}{llll}2 & 218 & 0 & 107\end{array}$

$\begin{array}{rrrrr}4 & 273 & 1 & 136\end{array}$

$\begin{array}{llll}14 & 492 & 0 & 127 \\ 22 & 851 & 4 & 212\end{array}$ $2071 \quad 812$

Golimumab

Emery et al., 2009 [52]

Inman et al., 2008 [60]

Kavanaugh et al., 2009

Kay et al., 2008 [64]

Keystone et al., 2009 [56]

Kremer et al., 2010 [51]

Takeuchi et, 2013 [36]

Tanaka et al., 2012 [45]

Weinblatt et al. 2013 [42]

Zhou et al., 2007 [70]

Fixed effect model

Random effects model

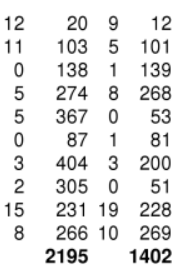

ffliximab

Abe et al., 2006 [74]

Baranauskaite et al., 2012 [46]

Leirisalo-Repo et al., 2013 [40]

Lipsky et al., 2000 [95]

Schiff et al., 2008 [66]

2004 [81]

Van den Bosch et al., 2002 [94]

van der Heijde et al., 2005 [79]

Westhovens et al., 2006 [73]

Zhang et al., 2006 [100]

Fixed effect model

Random effects model

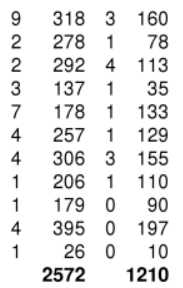

Fixed effect mode

$\begin{array}{lll}\text { Fixed effect model } & 13430 & 7366 \\ \text { Random effects model } & & \end{array}$

$\begin{array}{llll}3 & 52 & 1 & 52\end{array}$

$\begin{array}{llll}2 & 57 & 0 & 58 \\ 3 & 50 & 4 & 49\end{array}$

$\begin{array}{llll}21 & 340 & 7 & 88\end{array}$

$\begin{array}{llll}765 & 3 & 110\end{array}$

$\begin{array}{llll}40 & 749 & 6 & 298\end{array}$

$2 \quad 20 \quad 0 \quad 20$

$\begin{array}{llll}2 & 201 & 0 & 78\end{array}$

$\begin{array}{rrrr}0 & 87 & 1 & 86\end{array}$ $2542 \quad 1249$

$13430 \quad 7366$

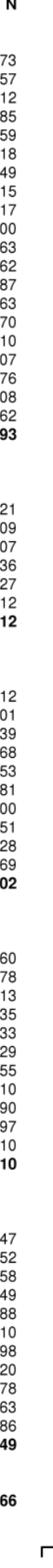

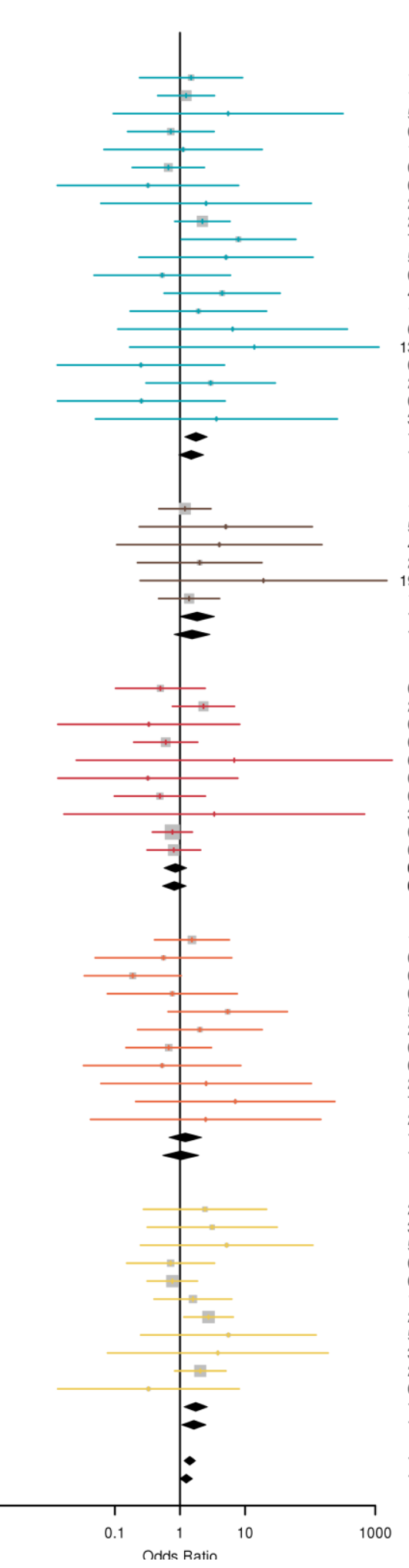

OR $\quad(95 \% \mathrm{Cl})$ Weight Weight

$1.48 \quad(0.24,9.12) \quad 1.2 \% \quad 1.4 \%$ $\begin{array}{llll}1.24 & (0.46,3.38) & 4.1 \% & 4.6 \%\end{array}$ $\begin{array}{lcrr}5.49 & (0.09,318.97) & 0.2 \% & 0.3 \% \\ 0.72 & (0.16,3.33) & 2.3 \% & 2.0 \%\end{array}$ $\begin{array}{llll}1.12 & (0.07,18.29) & 0.6 \% & 0.6 \%\end{array}$ $\begin{array}{llll}0.66 & (0.19,2.37) & 3.5 \% & 2.9 \%\end{array}$ $\begin{array}{llll}0.32 & (0.01,7.93) & 0.9 \% & 0.5 \%\end{array}$ $\begin{array}{llll}2.21 & (0.83,5.85) & 3.5 \% & 4.9 \%\end{array}$ $\begin{array}{llll}7.90 & (1.04,60.00) & 0.8 \% & 1.1 \%\end{array}$ $5.09(0.24,110.32) \quad 0.3 \% \quad 0.5 \%$ $0.53 \quad(0.05,5.94) \quad 1.1 \% \quad 0.8 \%$ \begin{tabular}{llll}
4.44 & $(0.57,34.42)$ & $0.8 \%$ & $1.1 \%$ \\
\hline
\end{tabular} $\begin{array}{llll}. .92 & (0.17,21.35) & 0.6 \% & 0.8 \% \\ 6.43 & (0.11,371.88) & 0.2 \% & 0.3 \%\end{array}$

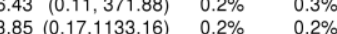
\begin{tabular}{llll}
0.25 & $(0.01,4.83)$ & $1.0 \%$ & $0.2 \%$ \\
\hline
\end{tabular} $\begin{array}{llll}0.256 & (0.01,-4.83) & 1.0 \% & 0.5 \% \\ & 0.30 \% & 0.9 \%\end{array}$ $\begin{array}{llll}0.25 & (0.01,4.93) & 1.0 \% & 0.5 \%\end{array}$

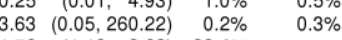
$\begin{array}{llll}1.76 & (1.18,2.62) & 23.4 \% & -\end{array}$

$\begin{array}{llll}1.19 & (0.48,2.98) & 5.0 \% & 5.5 \%\end{array}$ $5.05(0.24,107.69) \quad 0.3 \% \quad 0.5 \%$ $\begin{array}{llll}4.02 & (0.11,151.19) & 0.3 \% & 0.4 \% \\ 2.01 & (0.22,18.14) & 0.8 \% & 1.0 \%\end{array}$ $\begin{array}{lll}9.16(0.24,1501.25) & 0.2 \% & 0.2 \%\end{array}$ $\begin{array}{llrr}1.38 & (0.47,4.05) & 3.7 \% & 4.0 \%\end{array}$ $\begin{array}{rrrr}1.83 & (1.00,3.38) & 10.2 \% & -- \\ 1.53 & (0.81,2.89) & -- & 11.5 \%\end{array}$

$\begin{array}{llll}0.50 & (0.10, \quad 2.44) & 2.7 \% & 1.8 \%\end{array}$ $\begin{array}{llll}2.30 & (0.77,6.86) & 2.7 \% & 3.9 \%\end{array}$ $\begin{array}{lllll}0.33 & (0.01, & 8.25) & 0.9 \% & 0.4 \% \\ 0.60 & (0.20, & 1.87) & 4.7 \% & 3.6 \%\end{array}$

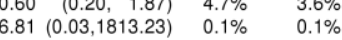
$0.32(0.01,7.71) \quad 0.9 \% \quad 0.5 \%$ $\begin{array}{llll}0.49 & (0.10,2.46) & 2.4 \% & 1.8 \%\end{array}$ $3.36(0.02,682.45) \quad 0.1 \% \quad 0.2 \%$

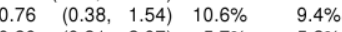
$0.80 \quad(0.31,2.07) \quad 5.7 \% \quad 5.2 \%$ $\begin{array}{lllrr}0.85 & (0.57, & 1.27) & 30.8 \% & - \\ 0.82 & (0.54,1.24) & -- & 26.9 \%\end{array}$

$\begin{array}{lllll}1.52 & (0.41, & 5.71) & 2.3 \% & 2.7 \%\end{array}$ $\begin{array}{llll}0.56 & (0.05,6.24) & 0.9 \% & 0.8 \% \\ 0.19 & (0.03,1.04) & 3.4 \% & 1.6 \%\end{array}$ $\begin{array}{lllll}0.19 & (0.03, & 1.04) & 3.4 \% & 1.6 \%\end{array}$ $\begin{array}{llll}0.76 & (0.08,7.55) & 0.9 \% & 0.9 \% \\ 5.40 & (0.66,44.46) & 0.7 \% & 1.0 \%\end{array}$ $\begin{array}{llll}2.02 & (0.22,18.29) & 0.8 \% & 1.0 \%\end{array}$ $\begin{array}{llll}0.67 & (0.15,3.04) & 2.3 \% & 2.0 \%\end{array}$ $\begin{array}{lllll}0.53 & (0.03,8.58) & 0.8 \% & 0.6 \%\end{array}$ $2.52(0.06,104.05) \quad 0.3 \% \quad 0.3 \%$ $7.07(0.21,238.93) \quad 0.3 \% \quad 0.4 \%$ $2.48(0.04,145.39) \quad 0.2 \% \quad 0.3 \%$ $\begin{array}{rrrr}1.21 & (0.68,2.16) & 12.8 \% & -- \\ 1.03 & (0.54,1.94) & -- & 11.5 \%\end{array}$

$2.42 \quad(0.27,21.33) \quad 0.8 \% \quad 1.0 \%$ $\begin{array}{llll}3.12 & (0.31,31.05) & 0.6 \% & 0.9 \% \\ 5 & 0.25 & \end{array}$ $\begin{array}{llll}5.22 & (0.25,109.94) & 0.3 \% & 0.5 \% \\ 0.72 & (0.15,3.39) & 2.3 \% & 1.9 \%\end{array}$ $\begin{array}{llll}0.72 & (0.15,3.39) & 2.3 \% & 1.9 \% \\ 0.76 & (0.31,1.85) & 6.2 \% & 5.9 \%\end{array}$

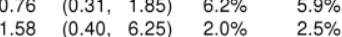

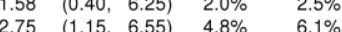

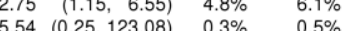

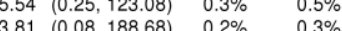

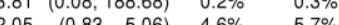
\begin{tabular}{llll}
0.33 & $(0.83,5.06)$ & $4.6 \%$ & $5.7 \%$ \\
\hline & $0.01,8.12)$ & $0.9 \%$ & $0.5 \%$
\end{tabular}

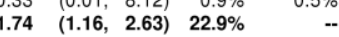
$\begin{array}{rrrr}1.63 & (1.16,2.63) & 22.9 \% & -- \\ & (1.07,2.50) & - & 25.6 \%\end{array}$ $\begin{array}{rrrr}1.41 & (1.16,1.73) & 100 \% & -- \\ 1.25 & (1.01,1.55) & -- & 100 \%\end{array}$ 
Figure 4A

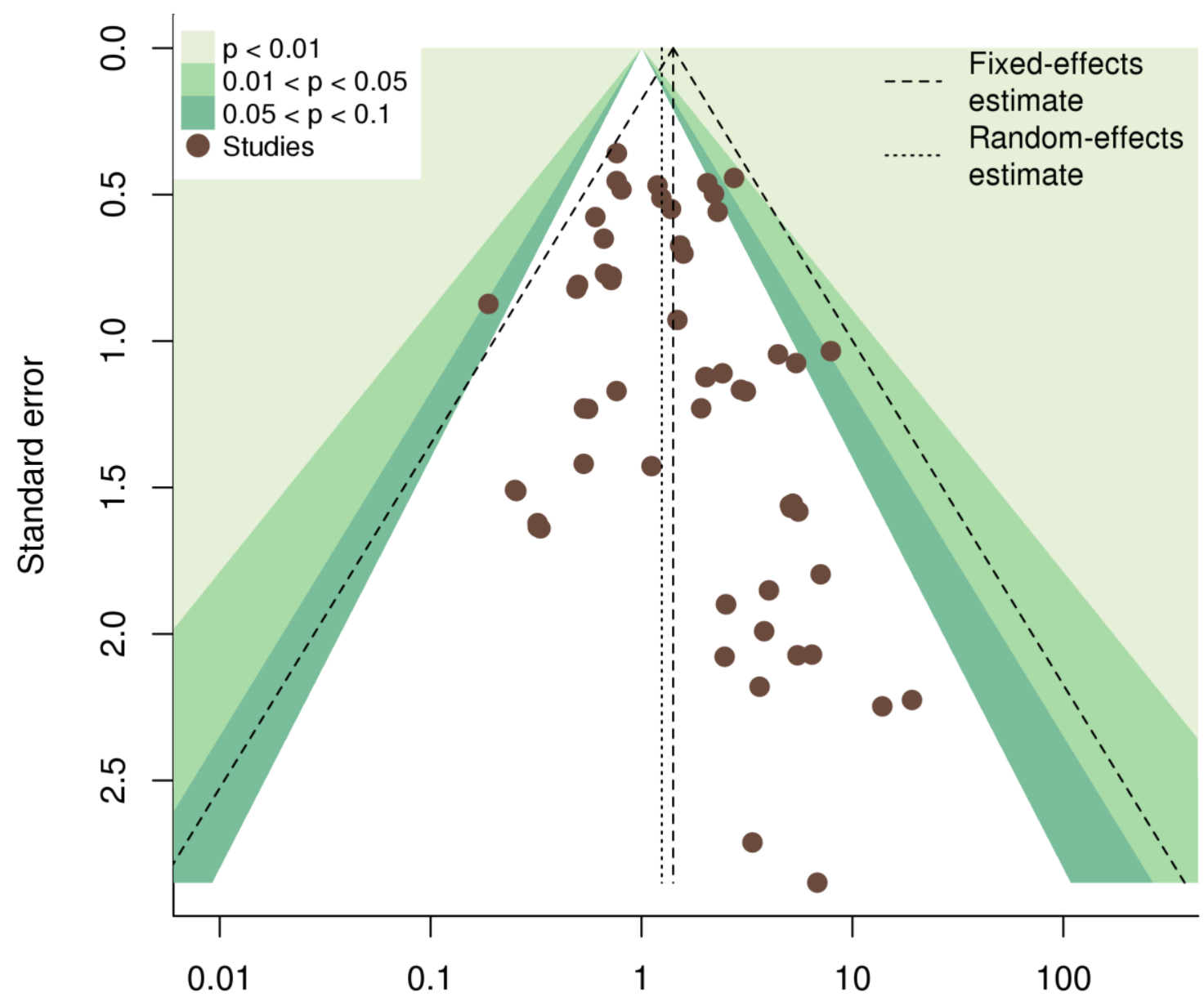

Odds Ratio 
Figure 4B

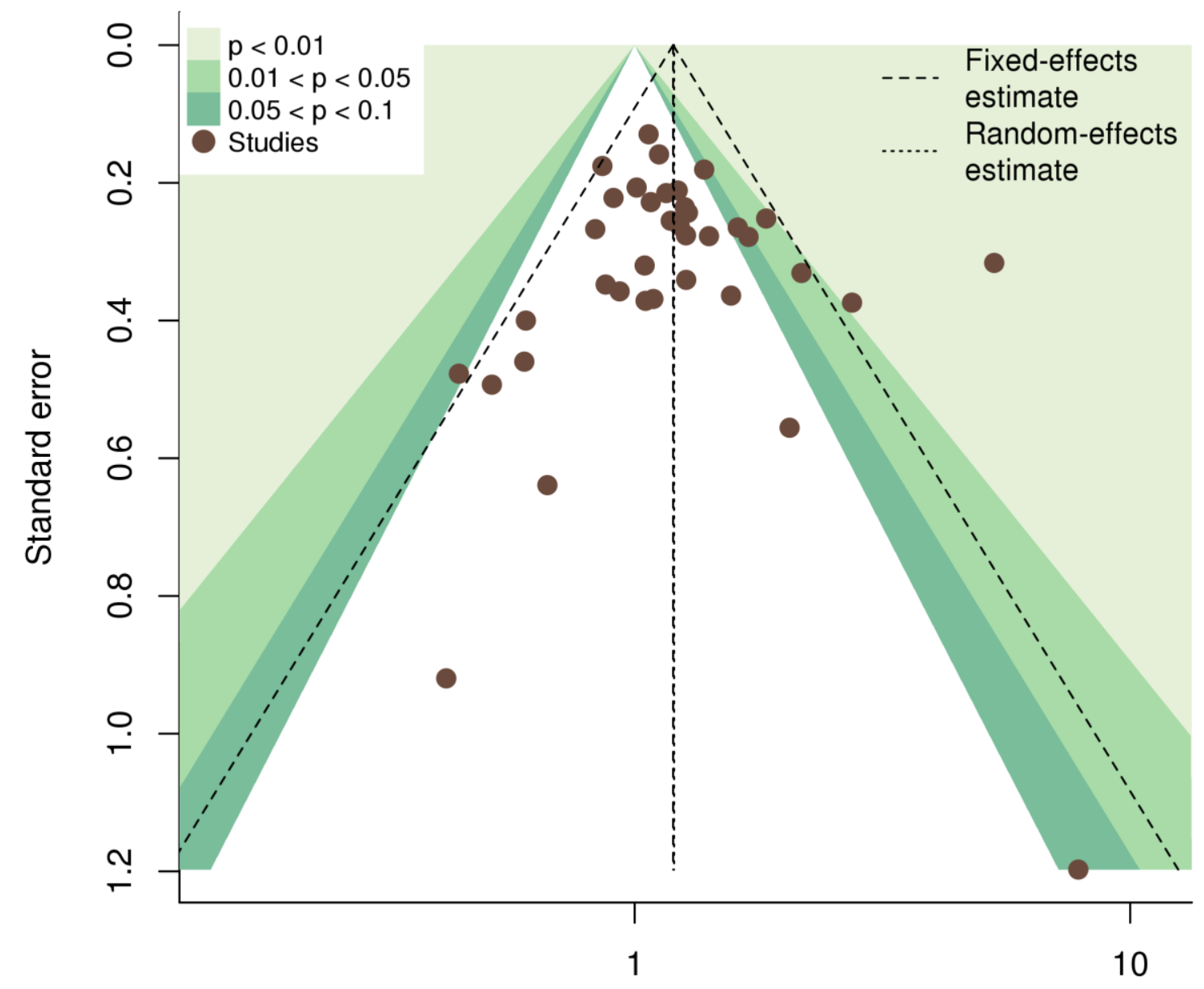

Odds Ratio 
Figure 5

$\underset{n}{\text { Treatment Control }} \mathrm{N} \mathrm{N}$

Randomized Controlled Trials

Adalimumab

Breedveld et al., 2006 [75] $\quad \begin{array}{lllll}1 & 268 & 0 & 257\end{array}$

Chen et al., 2009 [54]

Kavanaugh et al., 2013 [43]

Keystone et al., 2004 [84]

Kim et al., 2007 [99]

et al., 2011 [48]

Fixed effect model

$\begin{array}{rrr}1 & 79 & 0 \\ 1381 & 1125\end{array}$

Random effects model

$\begin{array}{llll}5 & 783 & 0 & 199\end{array}$

Certolizumab

Smolen et al., 2009 [57]

Fixed effect model

$\begin{array}{rrr}492 & 0 & 127 \\ 1275 & 326\end{array}$

Random effects model

$1103 \quad 0 \quad 101$

Etanercept

2009 [62]

$\begin{array}{lllll}\text { van der Heijde et al., } 2007 \text { [67] } & 1 & 231 & 0 & 228 \\ \text { Fixed effect model } & 334 & & 329\end{array}$

$131800 \quad 160$

Golimumab

Emery et al., 2009 [52]

Kremer et al., 2010 [51]

$\begin{array}{lll}257 & 0 & 129 \\ \mathbf{5 7 5} & \mathbf{2 8 9}\end{array}$

Infliximab

Baranauskaite et al., 2012 [46] $\quad \begin{array}{lllll}1 & 57 & 0 & 58\end{array}$

Braun et al., 2002 [93] $\quad 1 \quad 340035$

Sieper et al., 2014 [33] $\quad 1 \begin{array}{llll}106 & 0 & 52\end{array}$

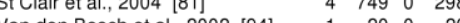

Van den Bosch et al., 2002 [94] $\begin{array}{rrrr}1 & 20 & 0 & 20\end{array}$

Westhovens et al., 2006 [73] $\quad 37 \begin{array}{rrrr}3 & 721 & 0 & 363\end{array}$

$\begin{array}{lrrrr}\text { Zhang et al., 2006 [100] } & 1 & 87 & 0 & 86 \\ \text { Fied effect model } & & 1774 & 912\end{array}$

Fixed ellect model

$5339 \quad 2981$

Fixed effect model

Random effects model

Heterogeneity: 1 -squared $=0 \%$, tau-squared $=0, p=1$

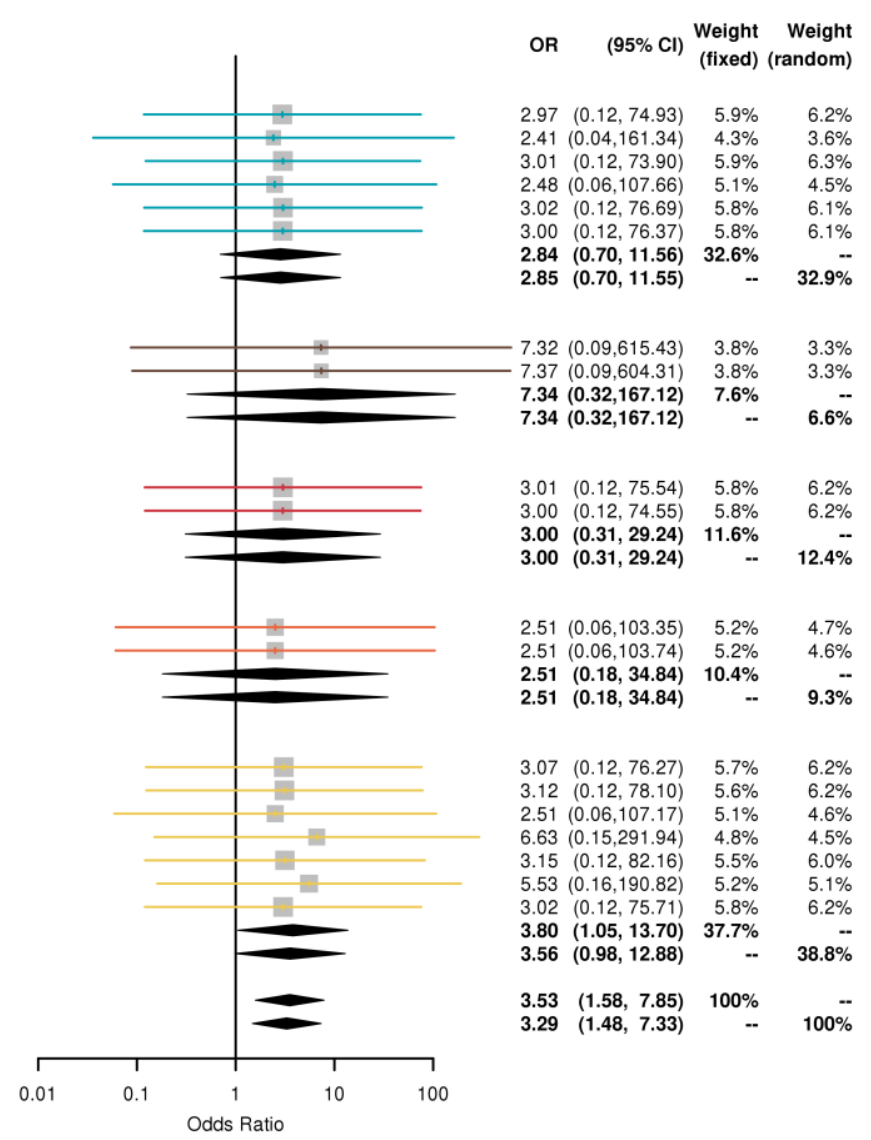


Figure 6

Treatment Control

Randomized Controlled Trials

Adalimumab

Kavanaugh et al., 2013 [43]

Keystone et al., 2004 [84]

Takeuchi et al., 2014

Fixed effect model

$\mathrm{n} \mathrm{N} N$

Random effects mode

$\begin{array}{llll}1 & 515 & 3 & 517\end{array}$

$\begin{array}{llll}2 & 419 & 0 & 200\end{array}$

$\begin{array}{rrr}171 & 1 & 163 \\ \mathbf{1 1 0 5} & \mathbf{8 8 0}\end{array}$

Etanercept

Emery et al., 2008 [63]

Fixed effect model

Random effects model

Infliximab

Schiff et al., 2008 [66]

Westhovens et al., 2006 [73]

Fixed effect mode

Random effects model

Fixed effect model

Random effects model

$+274+158$

$\begin{array}{rrr}274 & 1 & 268 \\ 274 & 268\end{array}$

$2 \begin{array}{llll}2 & 165 & 0 & 110\end{array}$

$\begin{array}{llll}1 & 721 & 0 & 363 \\ 886 & 473\end{array}$

$2265 \quad 1621$

Heterogeneity: $I$-squared $=0 \%$, tau-squared $=0, p=0.6501$

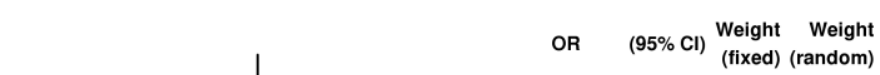

$\mid$ (fixed) (random)

$0.33 \quad(0.03,3.22) \quad 40.6 \%$

$3.97(0.10,153.52) \quad 50 \%-31.0 \%$

$0.33(0.01,7.86) \quad 20.6 \% \quad 15.7 \%$

$\begin{array}{lrrr}0.65 & (0.16,2.61) & 67.1 \% & -. \\ 0.55 & (0.11,2.85) & - & 58.6 \%\end{array}$

$0.33 \quad(0.01,8.03) \quad 20.5 \% \quad 15.6 \%$

$.33(0.01,8.03) \quad 20.5 \%$

$0.33(0.01,8.03) \quad-\quad 15.6 \%$

$4.39(0.16,123.48) \quad 6.4 \% \quad 14.3 \%$

$2.51(0.06,102.84) \quad 6.0 \% \quad 11.5 \%$

$\begin{array}{rrrr}3.48 & (0.29,41.27) & 12.4 \% & - \\ 3.42 & (0.29,40.90) & - & 25.8 \%\end{array}$

$0.94 \quad(0.33,2.64) \quad 100 \%$

$\begin{array}{rrrr}0.81 & (0.23,2.87) & -- & 100 \%\end{array}$ 
Figure 7

Randomized Controlled Trials

Adalimumab

Fleischmann et al., 2012 [47] Furst et al., 2003 [87]

Genovese et al., 2007 [69]

Huang et al., 2014 [34]

Kavanaugh et al., 2013 [43]
Keystone et al., 2004 [84]

Keystone et al., 2004 [84]

Kim et al., 2007 [99]

Miyasaka et al., $2008[65]$
Sieper et al., $2013[39]$

Sieper et al., 2013 [39]

Takeuchi et al., 2014 [35]
van der Heijde et al., 2006 [72]

Fixed effect mode

Random effects model

Certolizumab

Choy et al., 2012 [44]

Landewè et al., 2014 [31]

Mease et al., 2014 [32

Smolen et al., 2009 [57]

Weinblatt et al., 2012 [37]

Fixed effect mode

Random effects model

Etanercept

Combe et al., 2009 [62]

Dougados et al., 2010 [50]

Gorman et al., 2002 [92]

van der Heijde et al., 2006 [71]

van der Heijde et al., 2007 [67]

Weinblatt et al., 1999 [98]
Weisman et al., 2007 [68]

Fixed effect model

Random effects mode

\section{Golimumab}

Emery et al., 2009 [52]

Inman et al., 2008 [60]

Kavanaugh et al., 2009 [55]

Kay et al., 2008 [64]

Keystone et al., 2009 [56]

Kremer et al., 2010 [51]

Smolen et al., 2009 [53]

Takeuchi et al., 2013 [36]

Tanaka et al., 2012 [45]

Weinblatt et al., 2013 [42]

Fixed effect model

Random effects mode

Infliximab

Abe et al., 2006 [74]

Braun et al., 2002 [93]

Kavanaugh et al., 2000 [97]

van der Heijde et al., 2005 [79]

Random effects model

Fixed effect mode

andom effects model

Random effects model
Treatment Control

$\begin{array}{llll}10 & 53 & 6 & 59\end{array}$

$\begin{array}{llll}66 & 318 & 157 & 318\end{array}$

$\begin{array}{llll}9 & 51 & 16 & 49\end{array}$ $\begin{array}{llll}25 & 229 & 12 & 115\end{array}$ $\begin{array}{lllll}91 & 515 & 184 & 517 \\ 48 & 419 & 9 & 200\end{array}$ $\begin{array}{llll}48 & 419 & 9 & 200\end{array}$ $\begin{array}{rrrr}24 & 65 & 22 & 63 \\ 108 & 265 & 32 & 87\end{array}$ $\begin{array}{rrrr}28 & 91 & 28 & 94\end{array}$ $\begin{array}{llll}59 & 171 & 48 & 163\end{array}$ $\begin{array}{llll}66 & 208 & 23 & 107\end{array}$ $\begin{array}{rr}208 & 23 \\ 2385 & 1772\end{array}$

$\begin{array}{llll}33 & 126 & 17 & 121\end{array}$ $\begin{array}{llll}35 & 218 & 14 & 107\end{array}$ $\begin{array}{llll}114 & 273 & 52 & 136\end{array}$ $\begin{array}{llll}122 & 492 & 26 & 127\end{array}$ $\begin{array}{rrrr}245 & 851 & 48 & 212 \\ \mathbf{1 9 6 0} & & \mathbf{7 0 3}\end{array}$ $\begin{array}{rrrr}60 & 103 & 21 & 101\end{array}$ $\begin{array}{rrrr}5 & 12 & 1 & 12\end{array}$ $\begin{array}{llll}10 & 20 & 12 & 20\end{array}$ $\begin{array}{rrrr}68 & 305 & 12 & 51 \\ 17 & 231 & 19 & 228\end{array}$ $\begin{array}{llll}17 & 231 & 19 & 228\end{array}$ $\begin{array}{rrrr}106 & 266 & 117 & 269\end{array}$ $996 \quad 711$ $\begin{array}{rrrr}104 & 318 & 52 & 160 \\ 132 & 278 & 28 & 78\end{array}$ $\begin{array}{llll}107 & 292 & 27 & 113\end{array}$ $\begin{array}{lllr}36 & 137 & 13 & 35\end{array}$ $\begin{array}{llll}50 & 178 & 32 & 133\end{array}$ $\begin{array}{llll}90 & 257 & 43 & 129\end{array}$

$\begin{array}{llll}79 & 306 & 43 & 155\end{array}$

$\begin{array}{llll}56 & 206 & 25 & 110\end{array}$

$\begin{array}{rrrr}62 & 179 & 35 & 90 \\ 96 & 395 & 41 & 197\end{array}$ $\begin{array}{rrr}395 & 41 & 197 \\ 2546 & 1200\end{array}$

$\begin{array}{llll}47 & 100 & 17 & 47\end{array}$

$\begin{array}{llll}12 & 34 & 18 & 35\end{array}$

$\begin{array}{rrrr}5 & 21 & 3 & 7 \\ 86 & 201 & 27 & 78\end{array}$ 35 167

$0.0605, p=0.0015$

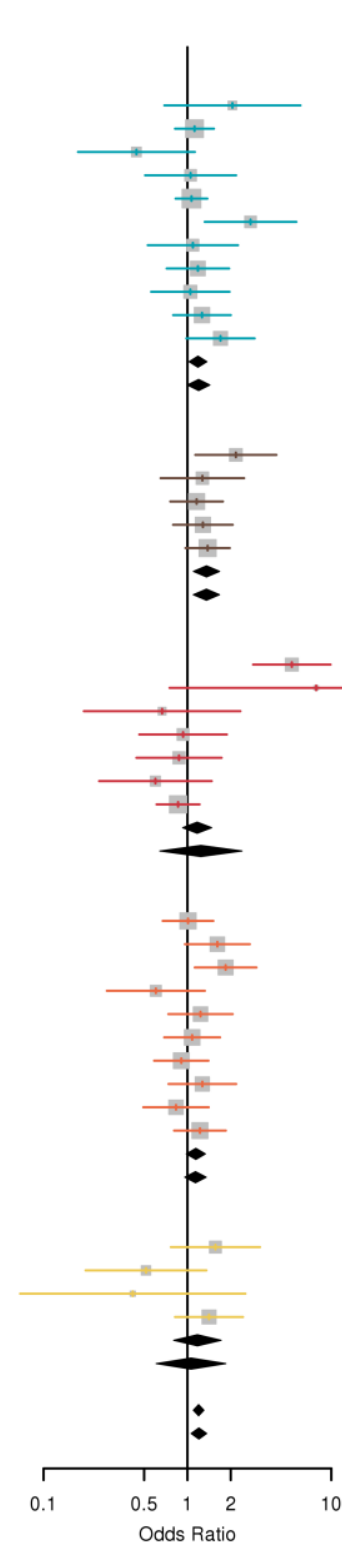

OR $\quad(95 \% \mathrm{Cl}) \underset{\text { Weight }}{\text { Weight }}$ (fixed) (random)

$2.05(0.69,6.10) \quad 0.5 \% \quad 1.1 \%$ $1.12(0.82,1.53) \quad 7.5 \% \quad 4.7 \%$

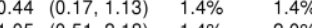
$1.05(0.51,2.18) \quad 1.4 \% \quad 2.0 \%$

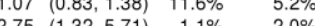

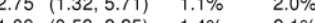
$\begin{array}{llll}1.18 & (0.72,1.95) & 2.9 \% & 3.2 \%\end{array}$ $1.05(0.56,1.96) \quad 1.9 \% \quad 2.5 \%$ $\begin{array}{llll}1.26 & (0.80,2.00) & 3.2 \% & 3.5 \%\end{array}$ $1.70(0.98,2.93) \quad 2.1 \% \quad 2.9 \%$ $\begin{array}{llrr}1.18 & (1.03,1.37) & 35.0 \% & -- \\ 1.20 & (1.00,1.43) & - & 30.7 \%\end{array}$

$2.17(1.13,4.15) \quad 1.3 \% \quad 2.4 \%$ $\begin{array}{llll}1.27 & (0.65,2.48) & 1.6 \% & 2.3 \%\end{array}$ $\begin{array}{llll}1.16 & (0.76,1.76) & 4.1 \% & 3.8 \%\end{array}$ $1.28(0.79,2.06) \quad 3.1 \% \quad 3.4 \%$ $1.38(0.97,1.97) \quad 5.5 \% \quad 4.3 \%$ $\begin{array}{rrrr}1.36 & (1.10,1.67) & 15.6 \% & - \\ 1.35 & (1.10,1.67) & - & 16.2 \%\end{array}$

$5.32(2.86,9.88) \quad 0.9 \%$

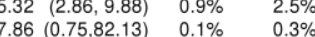
$0.67(0.19,2.33) \quad 0.6 \% \quad 0.9 \%$ $\begin{array}{llll}0.93 & (0.46,1.88) & 1.6 \% & 2.1 \% \\ 0.87 & (0.44,1.73) & 1.8 \% & 2.2 \%\end{array}$ $\begin{array}{llll}0.87 & (0.44,1.73) & 1.8 \% & 2.2 \% \\ 0.80 & & \end{array}$ $\begin{array}{llll}0.60 & (0.24,1.47) & 1.2 \% & 1.5 \% \\ & 0.86 & \end{array}$ $.17(0.93,1.47) \quad 13.2 \%$ $1.24(0.64,2.40)$ $1.01 \quad(0.67,1.51) \quad 4.7 \% \quad 3.9 \%$

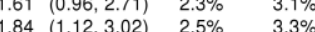
$0.60(0.28,1.32) \quad 1.5 \%-1.8 \%$ $1.23(0.74,206) \quad 2.6 \% \quad 3.1 \%$ $1.08(0.69 .1 .69) \quad 3.7 \% \quad 3.6 \%$ $0.91(0.59,1.40) \quad 4.3 \%-3.7 \%$ $1.27(0.74,2.18) \quad 2.4 \% \quad 3.0 \%$ $0.83(0.49,1.41) \quad 3.1 \% \quad 3.1 \%$ $032(0.81,1.85) \quad 4.2 \% \quad 3.1 \%$ $1.14(0.98,1.33)-31.3 \%$ $\begin{array}{llrr}1.14 & (0.98,1.33) & 31.3 \% & - \\ 1.14 & (0.96,1.35) & -- & 32.4 \%\end{array}$

$1.56(0.77,3.19) \quad 1.2 \% \quad 2.1 \%$ $0.52(0.20,1.35) \quad 1.2 \% \quad 1.3 \%$ $\begin{array}{lll}0.42 & (0.07,2.53) & 0.3 \%\end{array}-0.4 \%$ $\begin{array}{llll}1.17 & (0.82,2.43) & 2.2 \% & 2.9 \%\end{array}$ $\begin{array}{rrrr}1.17 & (0.80,1.72) & 5.0 \% & - \\ 1.06 & (0.61,1.85) & -- & 6.8 \%\end{array}$

$1.20(1.10,1.30) \quad 100 \%$ $1.20(1.06,1.36) \quad-\quad 100 \%$ 
Figure 8

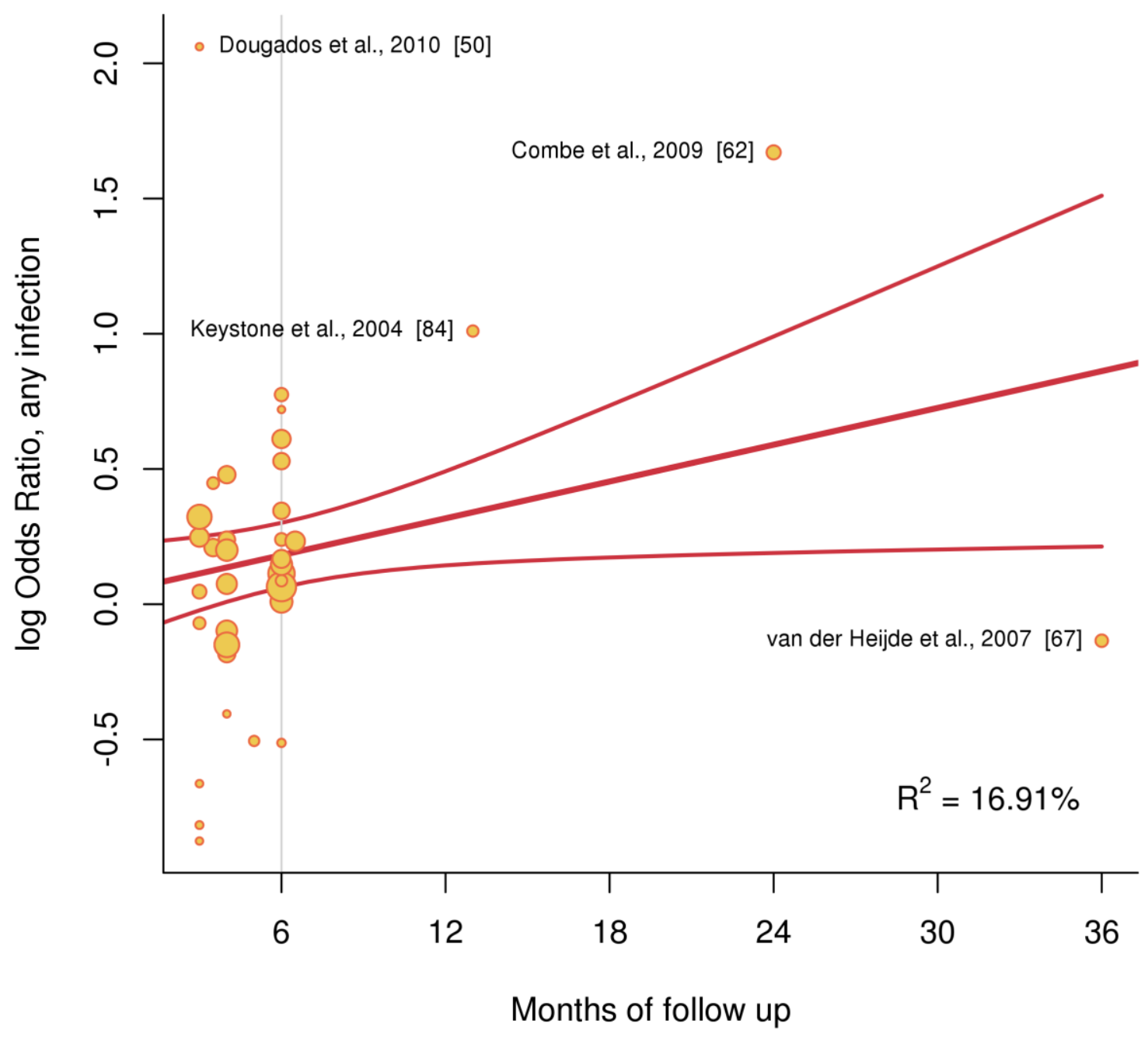


Table 1. Characteristics of the RCTs included in the meta-analysis $(n=71)$.

\begin{tabular}{|c|c|c|c|c|c|c|c|c|}
\hline Study & Acronym & Disease & Study arms & Intervention parameters & $\begin{array}{l}\text { Patients } \\
\text { randomize } \\
\text { d }\end{array}$ & $\begin{array}{l}\text { Follow- } \\
\text { up } \\
\text { duration } \\
\text { (months) }\end{array}$ & $\begin{array}{l}\text { Age of } \\
\text { patients } \\
\text { (years) }\end{array}$ & $\begin{array}{c}\text { Disease } \\
\text { duration } \\
\text { (months) }\end{array}$ \\
\hline \multirow{3}{*}{ Abe et al., 2006 [74] } & & \multirow{3}{*}{ RA } & IFX+MTX & $3 \mathrm{mg} / \mathrm{kg}, \mathrm{wk}: 0,2,6$ & $(n=49)$ & 3.5 & 55.2 & 9.1 \\
\hline & & & IFX+MTX & $10 \mathrm{mg} / \mathrm{kg}$ wk: $0,2,6$ & $(n=51)$ & 3.5 & 56.8 & 7.1 \\
\hline & & & $\mathrm{PBO}+\mathrm{MTX}$ & & $(n=47)$ & 3.5 & 55.1 & 7.5 \\
\hline \multirow{2}{*}{ Antoni et al., 2005 [80] } & \multirow{2}{*}{ IMPACT 2} & \multirow{2}{*}{ PsA } & IFX+MTX & $5 \mathrm{mg} / \mathrm{kg}, \mathrm{wk}: 0,2,6,14$ & $(\mathrm{n}=100)$ & 6 & 47.1 & 100.8 \\
\hline & & & $\mathrm{PBO}+\mathrm{MTX}$ & & $(\mathrm{n}=100)$ & 6 & 46.5 & 90.0 \\
\hline \multirow{2}{*}{ Antoni et al., 2005 [78] } & \multirow{2}{*}{ IMPACT 1} & \multirow{2}{*}{ PsA } & IFX+MTX & $5 \mathrm{mg} / \mathrm{kg}$, wk: $0,2,6,14$ & $(n=52)$ & 4 & 45.7 & 140.4 \\
\hline & & & PBO+MTX & & $(n=52)$ & 4 & 45.2 & 132.0 \\
\hline \multirow{2}{*}{ Baranauskaite et al., 2012 [46] } & \multirow{2}{*}{ RESPOND } & \multirow{2}{*}{ PsA } & IFX+MTX & $5 \mathrm{mg} / \mathrm{kg}, \mathrm{wk}: 0,2,6,14$ & $(n=57)$ & 4 & 40.1 & 33.6 \\
\hline & & & MTX & & $(n=58)$ & 4 & 42.3 & 44.4 \\
\hline \multirow{2}{*}{ Barkham et al., 2010 [49] } & & \multirow{2}{*}{ AS } & ETA+MTX & $25 \mathrm{mg}$ & $(n=20)$ & 3 & 40.8 & $132.0^{*}$ \\
\hline & & & PBO+MTX & & $(n=12)$ & 3 & 39.4 & $240.0 *$ \\
\hline \multirow{2}{*}{ Bejarano et al., 2008 [61] } & & \multirow{2}{*}{ RA } & $\mathrm{ADA}+\mathrm{MTX}$ & NR & $(n=75)$ & 56 & 47.0 & 9.5 \\
\hline & & & PBO+MTX & & $(n=73)$ & 56 & 47.0 & 7.9 \\
\hline \multirow{2}{*}{ Brandt et al., 2003 [90] } & & \multirow{2}{*}{ AS } & ETA & $25 \mathrm{mg} / 2 \mathrm{wk}$ & $(n=16)$ & 7.5 & 39.8 & 14.9 \\
\hline & & & PBO & & $(n=17)$ & 7.5 & 32.0 & 11.4 \\
\hline \multirow{2}{*}{ Braun et al., 2002 [93] } & & \multirow{2}{*}{ AS } & IFX & $5 \mathrm{mg} / \mathrm{kg}$, wk: $0,2,6$ & $(n=34)$ & 3 & 40.6 & 16.4 \\
\hline & & & $\mathrm{PBO}$ & & $(n=35)$ & 3 & 39.0 & 14.9 \\
\hline \multirow{2}{*}{ Breedveld et al., 2006 [75] } & \multirow{2}{*}{ PREMIER } & \multirow{2}{*}{ RA } & $\mathrm{ADA}+\mathrm{MTX}$ & $40 \mathrm{mg} / 2 \mathrm{wks}$ & $(n=268)$ & 24 & 51.9 & 8.4 \\
\hline & & & PBO+MTX & & $(n=257)$ & 24 & 52.0 & 9.6 \\
\hline \multirow{2}{*}{ Chen et al., 2009 [54] } & & \multirow{2}{*}{ RA } & $\mathrm{ADA}+\mathrm{MTX}$ & $40 \mathrm{mg} / 2 \mathrm{wks}$ & $(n=35)$ & 3 & $53.0^{*}$ & $74.4^{*}$ \\
\hline & & & PBO+MTX & & $(n=12)$ & 3 & $53.0^{*}$ & $99.6^{*}$ \\
\hline \multirow{2}{*}{ Choy et al., 2012 [44] } & & \multirow{2}{*}{ RA } & CTP+MTX & $400 \mathrm{mg} / 4 \mathrm{wks}$ & $(n=126)$ & 6 & 53.0 & 9.4 \\
\hline & & & PBO+MTX & & $(\mathrm{n}=121)$ & 6 & 55.6 & 9.9 \\
\hline \multirow{2}{*}{ Combe et al., 2009 [62] } & & \multirow{2}{*}{ RA } & ETA & $25 \mathrm{mg} / \mathrm{twice}$ per wk & $(n=103)$ & 24 & 50.6 & 78.0 \\
\hline & & & $\mathrm{PBO}$ & & $(n=101)$ & 24 & 53.3 & 67.2 \\
\hline Davis et al., 2003 [89] & & $\mathrm{AS}$ & ETA+DMARDs & $25 \mathrm{mg} / 2 \mathrm{wks}$ & $(n=138)$ & 6 & $42.1^{*}$ & $10.1^{*}$ \\
\hline
\end{tabular}




\begin{tabular}{|c|c|c|c|c|c|c|c|c|}
\hline & & & PBO+DMARDs & & $(\mathrm{n}=139)$ & 6 & $41.9 *$ & $10.5^{*}$ \\
\hline \multirow{2}{*}{ Detert et al., 2013 [41] } & & \multirow{2}{*}{ RA } & $\mathrm{ADA}+\mathrm{MTX}$ & \multirow[t]{2}{*}{$40 \mathrm{mg}$ eow } & $(n=87)$ & 6 & 47.2 & 1.8 \\
\hline & & & $\mathrm{PBO}+\mathrm{MTX}$ & & $(n=85)$ & 6 & 52.5 & 1.6 \\
\hline \multirow{2}{*}{ Dougados et al., 2011 [50] } & \multirow{2}{*}{ SPINE } & \multirow{2}{*}{ AS } & ETA+DMARDs & \multirow[t]{2}{*}{$50 \mathrm{mg} / \mathrm{wk}$} & $(n=39)$ & 3 & 46.0 & 228.0 \\
\hline & & & PBO+DMARDs & & $(n=43)$ & 3 & 48.0 & 276.0 \\
\hline \multirow{3}{*}{ Emery et al., 2009 [52] } & \multirow{3}{*}{ GO BEFORE } & \multirow{3}{*}{ RA } & GLM+MTX & $100 \mathrm{mg} / 4 \mathrm{wks}$ & $(n=159)$ & 6 & 50.2 & 43.2 \\
\hline & & & GLM+MTX & $50 \mathrm{mg} / 4 \mathrm{wks}$ & $(n=159)$ & 6 & 50.9 & 42.0 \\
\hline & & & $\mathrm{PBO}+\mathrm{MTX}$ & & $(\mathrm{n}=160)$ & 6 & 48.6 & 34.8 \\
\hline \multirow{2}{*}{ Emery et al., 2008 [63] } & \multirow{2}{*}{ COMET } & \multirow{2}{*}{ RA } & ETA+MTX & $50 \mathrm{mg} / \mathrm{wk}$ & $(n=274)$ & 24 & 50.5 & 8.8 \\
\hline & & & PBO+MTX & & $(n=268)$ & 24 & 52.3 & 9.3 \\
\hline \multirow{2}{*}{ Fleischmann et al., 2012 [47] } & & \multirow{2}{*}{ RA } & $\mathrm{ADA}$ & $40 \mathrm{mg}$ eow & $(n=53)$ & 6 & 54.0 & $7.7^{*}$ \\
\hline & & & PBO & & $(n=59)$ & 6 & 53.0 & $10.8^{*}$ \\
\hline \multirow{2}{*}{ Fleischmann et al., 2009 [58] } & \multirow{2}{*}{ FAST4WARD } & \multirow{2}{*}{ RA } & CTP & $400 \mathrm{mg} / 4 \mathrm{wks}$ & $(\mathrm{n}=111)$ & 6 & 52.7 & 104.4 \\
\hline & & & PBO & & $(\mathrm{n}=109)$ & 6 & 54.9 & 124.8 \\
\hline \multirow{2}{*}{ Furst et al., 2003 [87] } & \multirow{2}{*}{ STAR } & \multirow{2}{*}{ RA } & ADA+DMARDs & $40 \mathrm{mg}$ eow & $(n=318)$ & 6 & 55.0 & 9.3 \\
\hline & & & PBO+DMARDs & & $(\mathrm{n}=318)$ & 6 & 55.8 & 11.5 \\
\hline \multirow{2}{*}{ Genovese et al., 2007 [69] } & & \multirow{2}{*}{ PsA } & ADA+DMARDs & $40 \mathrm{mg} / 2 \mathrm{wks}$ & $(n=51)$ & 3 & 50.4 & 90.0 \\
\hline & & & PBO+DMARDs & & $(n=49)$ & 3 & 47.7 & 86.4 \\
\hline \multirow{2}{*}{ Gorman et al., 2002 [92] } & & \multirow{2}{*}{ AS } & ETA+DMARDs & $25 \mathrm{mg} / 2 \mathrm{wks}$ & $(n=20)$ & 4 & 38.0 & 180.0 \\
\hline & & & PBO+DMARDs & & $(n=20)$ & 4 & 39.0 & 144.0 \\
\hline \multirow{2}{*}{ Huang et al., 2014 [34] } & & \multirow{2}{*}{ AS } & ADA+DMARDs & $40 \mathrm{mg}$ & $(n=229)$ & 3 & 30.1 & 36.0 \\
\hline & & & PBO+DMARDs & & $(\mathrm{n}=115)$ & 3 & 29.6 & 36.0 \\
\hline & & & GLM+DMARDs & $50 \mathrm{mg}$ & $(n=138)$ & 4 & $38.0 *$ & $61.8^{*}$ \\
\hline Inman et al., 2008 [60] & GO RAISE & AS & GLM+DMARDs & $100 \mathrm{mg}$ & $(n=140)$ & 4 & $38.0 *$ & $62.4^{*}$ \\
\hline & & & PBO+DMARDs & & $(\mathrm{n}=78)$ & 4 & $41.0^{*}$ & $87.0^{*}$ \\
\hline Kavanaugh et l 2013 & OPTIMA & RA & $\mathrm{ADA}+\mathrm{MTX}$ & $40 \mathrm{mg}$ & $(n=515)$ & 6 & 50.7 & 4.0 \\
\hline Kavanaugh et al., 2013 [43] & OPTIMA & RA & $\mathrm{PBO}+\mathrm{MTX}$ & & $(n=517)$ & 6 & 50.4 & 4.5 \\
\hline & & & GLM & $50 \mathrm{mg} / 4 \mathrm{wks}$ & $(n=146)$ & 6 & 45.7 & 86.4 \\
\hline Kavanaugh et al., 2009 [55] & GO REVEAL & PsA & GLM & $100 \mathrm{mg} / 4 \mathrm{wks}$ & $(n=146)$ & 6 & 48.2 & 92.4 \\
\hline & & & $\mathrm{PBO}$ & & $(\mathrm{n}=113)$ & 6 & 47.0 & 91.2 \\
\hline & & & IFX+MTX & $5 \mathrm{mg} / \mathrm{kg}$ single injection & $(n=7)$ & 3 & 47.0 & 88.8 \\
\hline & & & IFX+MTX & $10 \mathrm{mg} / \mathrm{kg}$ single injection & $(n=7)$ & 3 & 53.0 & 90.0 \\
\hline Kavanaugh et al., 2000 [97] & & RA & IFX+MTX & $20 \mathrm{mg} / \mathrm{kg}$ single injection & $(n=7)$ & 3 & 37.4 & 58.8 \\
\hline & & & PBO+MTX & & $(n=7)$ & 3 & 44.6 & 58.8 \\
\hline Kay et al., 2008 [64] & & $\mathrm{RA}$ & GLM+MTX & $50 \mathrm{mg} / 4 \mathrm{wks}$ & $(n=35)$ & 5 & $57.0^{*}$ & $98.4^{*}$ \\
\hline
\end{tabular}




\begin{tabular}{|c|c|c|c|c|c|c|c|c|}
\hline & & & GLM+MTX & $50 \mathrm{mg} / 2 \mathrm{wks}$ & $(\mathrm{n}=34)$ & 5 & $48.0 *$ & $98.4 *$ \\
\hline & & & GLM+MTX & $100 \mathrm{mg} / 4 \mathrm{wks}$ & $(n=34)$ & 5 & $57.5^{*}$ & $75.6^{*}$ \\
\hline & & & GLM+MTX & $100 \mathrm{mg} / 2 \mathrm{wks}$ & $(n=34)$ & 5 & $53.5^{*}$ & $108.0^{*}$ \\
\hline & & & $\mathrm{PBO}+\mathrm{MTX}$ & & $(\mathrm{n}=35)$ & 5 & $52.0 *$ & $67.2 *$ \\
\hline & & & GLM+MTX & $100 \mathrm{mg} / 4 \mathrm{wks}$ & $(n=89)$ & 3.5 & $50.0^{*}$ & $80.4^{*}$ \\
\hline Keystone et al., 2009 [56] & GO FORWARD & RA & GLM+MTX & $50 \mathrm{mg} / 4 \mathrm{wks}$ & $(n=89)$ & 3.5 & $52.0^{*}$ & $54.0 *$ \\
\hline & & & $\mathrm{PBO}+\mathrm{MTX}$ & & $(n=133)$ & 3.5 & $52.0 *$ & $78.0 *$ \\
\hline & & & $\mathrm{CTP}+\mathrm{MTX}$ & $200 \mathrm{mg} / 2 \mathrm{wks}$ & $(n=393)$ & 13 & 51.4 & 73.2 \\
\hline Keystone et al., 2008 [59] & RAPID 1 & RA & $\mathrm{CTP}+\mathrm{MTX}$ & $400 \mathrm{mg} / 2 \mathrm{wks}$ & $(n=390)$ & 13 & 52.4 & 74.4 \\
\hline & & & $\mathrm{PBO}+\mathrm{MTX}$ & & $(n=199)$ & 13 & 52.2 & 74.4 \\
\hline & & & $\mathrm{ADA}+\mathrm{MTX}$ & $40 \mathrm{mg}$ eow & $(n=419)$ & 4.3 & 56.1 & 11.0 \\
\hline Keystone et al., 2004 [84] & & RA & $\mathrm{PBO}+\mathrm{MTX}$ & & $(n=200)$ & 4.3 & 56.1 & 10.9 \\
\hline & & & ETA+MTX & $50 \mathrm{mg} / \mathrm{wk}$ & $(n=214)$ & 2 & $53.0^{*}$ & $9.0^{*}$ \\
\hline Keystone et al., 2004 [86] & & RA & ETA+MTX & $25 \mathrm{mg} / 2 \mathrm{wks}$ & $(n=153)$ & 2 & $52.0 *$ & $8.2^{*}$ \\
\hline & & & PBO+MTX & & $(n=53)$ & 2 & $54.0 *$ & $10.8^{*}$ \\
\hline Kimet al 2007 ropr & & $\mathrm{PA}$ & $\mathrm{ADA}+\mathrm{MTX}$ & $40 \mathrm{mg}$ & $(n=65)$ & 6 & 48.5 & 6.8 \\
\hline Kim et al., 200/ [99] & & KA & $\mathrm{PBO}+\mathrm{MTX}$ & & $(n=63)$ & 6 & 49.8 & 6.9 \\
\hline & & & GLM+MTX & $2 \mathrm{mg} / \mathrm{kg}$, wk: $0,12,24,36,48$ & $(n=129)$ & 12 & 49.7 & 97.2 \\
\hline Kremer et al., 2010 [51] & & RA & GLM+MTX & $4 \mathrm{mg} / \mathrm{kg}, \mathrm{wk}: 0,12,24,36,48$ & $(\mathrm{n}=128)$ & 12 & 49.6 & 112.8 \\
\hline & & & $\mathrm{PBO}+\mathrm{MTX}$ & & $(n=129)$ & 12 & 50.2 & 88.8 \\
\hline & & & CTP+MTX & $200 \mathrm{mg} / \mathrm{wk}: 0,2,4$ & $(n=111)$ & 6 & 39.1 & NR \\
\hline Landewè et al., 2014 [31] & RAPID & AS & CTP+MTX & $400 \mathrm{mg} / \mathrm{wk}: 0,2,4$ & $(n=107)$ & 6 & 39.8 & NR \\
\hline & & & $\mathrm{PBO}+\mathrm{MTX}$ & & $(\mathrm{n}=107)$ & 6 & 39.9 & NR \\
\hline & & & IFX & $3 \mathrm{mg} / \mathrm{kg} / \mathrm{wk}: 4,6,10,18,26$ & $(\mathrm{n}=50)$ & 24 & 47.0 & 4.0 \\
\hline Leirisalo-Repo et al., 2013 [40] & NEO RACO & RA & PBO & & $(n=49)$ & 24 & 46.0 & 4.0 \\
\hline & & & IFX+MTX & $3 \mathrm{mg} / \mathrm{kg} / 4 \mathrm{wks}$ & $(\mathrm{n}=86)$ & 13.5 & 52.0 & 9.0 \\
\hline & & & IFX+MTX & $10 \mathrm{mg} / \mathrm{kg} / 8 \mathrm{wks}$ & $(\mathrm{n}=87)$ & 13.5 & 54.0 & 11.0 \\
\hline Lipsky et al., 2000 [95] & ATTRACT & RA & IFX+MTX & $10 \mathrm{mg} / \mathrm{kg} / 4 \mathrm{wks}$ & $(\mathrm{n}=81)$ & 13.5 & 52.0 & 12.0 \\
\hline & & & IFX+MTX & $3 \mathrm{mg} / \mathrm{kg} / 8 \mathrm{wks}$ & $(n=86)$ & 13.5 & 54.0 & 10.0 \\
\hline & & & $\mathrm{PBO}+\mathrm{MTX}$ & & $(\mathrm{n}=88)$ & 13.5 & 51.0 & 11.0 \\
\hline & & & IFX+MTX & $5 \mathrm{mg} / \mathrm{kg} / \mathrm{wk}: 0,2,6,14,22$ & $(n=28)$ & 7.5 & $41 *$ & $8^{*}$ \\
\hline Marzo-Ortega et al., 2005 [77] & & AS & PBO+MTX & & $(n=14)$ & 7.5 & $39 *$ & $10^{*}$ \\
\hline & & & CTP+MTX & $200 \mathrm{mg} / 2 \mathrm{wks}$ & $(n=138)$ & 6 & 48.2 & 115.2 \\
\hline Mease et al., 2014 [32] & RAPID PsA & PsA & CTP+MTX & $400 \mathrm{mg} / 4 \mathrm{wks}$ & $(n=135)$ & 6 & 47.1 & 97.2 \\
\hline & & & $\mathrm{PBO}+\mathrm{MTX}$ & & $(n=136)$ & 6 & 47.3 & 94.8 \\
\hline
\end{tabular}




\begin{tabular}{|c|c|c|c|c|c|c|c|c|}
\hline \multirow{2}{*}{ Mease et al., 2005 [75] } & & \multirow{2}{*}{ PsA } & $\mathrm{ADA}+\mathrm{MTX}$ & \multirow[t]{2}{*}{$40 \mathrm{mg} / 2 \mathrm{wk}$} & $(n=151)$ & 6 & 48.6 & 117.6 \\
\hline & & & $\mathrm{PBO}+\mathrm{MTX}$ & & $(n=162)$ & 6 & 49.2 & 110.4 \\
\hline \multirow{2}{*}{ Mease et al., 2004 [82] } & & \multirow{2}{*}{ PsA } & ETA+MTX & \multirow[t]{2}{*}{$25 \mathrm{mg} /$ twice wk } & $(n=87)$ & 6 & 47.6 & 108.0 \\
\hline & & & PBO+MTX & & $(n=81)$ & 6 & 47.3 & 110.4 \\
\hline \multirow{2}{*}{ Mease et al., 2000 [96] } & & \multirow{2}{*}{ PsA } & ETA+MTX & \multirow[t]{2}{*}{$25 \mathrm{mg} /$ twice wk } & $(n=30)$ & 3 & $46.0 *$ & $108 *$ \\
\hline & & & $\mathrm{PBO}+\mathrm{MTX}$ & & $(n=30)$ & 3 & $43.5^{*}$ & $114 *$ \\
\hline \multirow{4}{*}{ Miyasaka et al., 2008 [65] } & \multirow{4}{*}{ CHANGE } & \multirow{4}{*}{ RA } & $\mathrm{ADA}$ & $80 \mathrm{mg} / 2 \mathrm{wks}$ & $(n=87)$ & 6 & 54.3 & 114.0 \\
\hline & & & $\mathrm{ADA}$ & $40 \mathrm{mg} / 2 \mathrm{wks}$ & $(n=91)$ & 6 & 56.9 & 118.8 \\
\hline & & & $\mathrm{ADA}$ & $20 \mathrm{mg} / 2 \mathrm{wks}$ & $(n=87)$ & 6 & 54.8 & 120.0 \\
\hline & & & $\mathrm{PBO}$ & & $(n=87)$ & 6 & 53.4 & 100.8 \\
\hline \multirow{3}{*}{ Rau et al., 2004 [83] } & & \multirow{3}{*}{$\mathrm{RA}$} & $\mathrm{ADA}+\mathrm{MTX}$ & $1 \mathrm{mg} / \mathrm{Kg}$ (iv) 0, 29 week & $(n=18)$ & 1.5 & 52.3 & 133.2 \\
\hline & & & $\mathrm{ADA}+\mathrm{MTX}$ & $1 \mathrm{mg} / \mathrm{Kg}$ (sc) 0, 29 week & $(n=18)$ & 1.5 & 53.3 & 127.2 \\
\hline & & & $\mathrm{PBO}+\mathrm{MTX}$ & & $(\mathrm{n}=18)$ & 1.5 & 54.1 & 138.0 \\
\hline \multirow{2}{*}{ Schiff et al., 2008 [66] } & \multirow{2}{*}{ ATTEST } & \multirow{2}{*}{ RA } & IFX+MTX & $0-3 \mathrm{mg} / \mathrm{kg} / 8 \mathrm{wks}$ & $(n=165)$ & 6 & 49.1 & 87.6 \\
\hline & & & $\mathrm{PBO}+\mathrm{MTX}$ & & $(\mathrm{n}=110)$ & 6 & 49.4 & 100.8 \\
\hline \multirow{2}{*}{ Sieper et al., 2014 [33] } & \multirow{2}{*}{ INFAST } & \multirow{2}{*}{ AS } & IFX & $5 \mathrm{mg} / \mathrm{kg}$, wk: $0,2,6,12,18,24$ & $(n=106)$ & 7 & 31.7 & 10.1 \\
\hline & & & PBO & & $(n=52)$ & 7 & 30.7 & 8.3 \\
\hline \multirow{2}{*}{ Sieper et al., 2013 [39] } & \multirow{2}{*}{ ABILITY 1} & \multirow{2}{*}{ AS } & ADA+DMARDs & $40 \mathrm{mg} / 1 \mathrm{wk}$ & $(\mathrm{n}=91)$ & 3 & 37.6 & 36.0 \\
\hline & & & PBO+DMARDs & & $(n=94)$ & 3 & 38.4 & 32.4 \\
\hline \multirow{3}{*}{ Smolen et al., 2009 [57] } & \multirow{3}{*}{ RAPID 2} & \multirow{3}{*}{ RA } & CTP+MTX & $400 \mathrm{mg} / 2 \mathrm{wks}$ & $(n=246)$ & 3 & 51.9 & 78.0 \\
\hline & & & $\mathrm{CTP}+\mathrm{MTX}$ & $200 \mathrm{mg} / 2 \mathrm{wks}$ & $(n=246)$ & 3 & 52.2 & 73.2 \\
\hline & & & $\mathrm{PBO}+\mathrm{MTX}$ & & $(n=127)$ & 3 & 51.5 & 67.2 \\
\hline \multirow{3}{*}{ Smolen et al., 2009 [53] } & & & GLM+DMARDs & $50 \mathrm{mg} / 4 \mathrm{wks}$ & $(n=153)$ & 4 & $55.0 *$ & $115.2 *$ \\
\hline & GO AFTER & RA & GLM+DMARDs & $100 \mathrm{mg} / 4 \mathrm{wks}$ & $(n=153)$ & 4 & $55.0 *$ & $104.4 *$ \\
\hline & & & PBO+DMARDs & & $(n=155)$ & 4 & $54.0 *$ & $117.6^{*}$ \\
\hline & & & ETA+MTX & $50 \mathrm{mg}$ & $(n=202)$ & 12 & 48.1 & 81.6 \\
\hline Smolen et al., 2013 [30] & PRESERVE & RA & ETA+MTX & $25 \mathrm{mg}$ & $(n=202)$ & 12 & 46.4 & 76.8 \\
\hline & & & $\mathrm{PBO}+\mathrm{MTX}$ & & $(n=200)$ & 12 & 48.3 & 87.6 \\
\hline & & & IFX+MTX & $3 \mathrm{mg} / \mathrm{kg} / 4 \mathrm{wks}$ & $(n=373)$ & 13.5 & 51.0 & 10 \\
\hline St Clair et al., 2004 [81] & & RA & IFX+MTX & $6 \mathrm{mg} / \mathrm{kg} / 4 \mathrm{wks}$ & $(n=376)$ & 13.5 & 50.0 & 11 \\
\hline & & & $\mathrm{PBO}+\mathrm{MTX}$ & & $(n=298)$ & 13.5 & 50.0 & 11 \\
\hline & & & $\mathrm{ADA}+\mathrm{MTX}$ & $40 \mathrm{mg}$ eow & $(n=171)$ & 6.5 & 54.0 & 3.6 \\
\hline Takeuch1 et al., 2014 [35] & HOPEFUL I & RA & $\mathrm{PBO}+\mathrm{MTX}$ & & $(n=163)$ & 6.5 & 54.0 & 3.6 \\
\hline Takeuchi et al 2013 & GO-MONO & RA & GLM & $50 \mathrm{mg}$ every $4 \mathrm{w}$ & $(n=102)$ & 4 & 52.9 & 97.2 \\
\hline rakeuchl el al., Z015 [56] & & RA & GLM & $100 \mathrm{mg}$ every $4 \mathrm{w}$ & $(n=104)$ & 4 & 51.6 & 112.8 \\
\hline
\end{tabular}




\begin{tabular}{|c|c|c|c|c|c|c|c|c|}
\hline & & & PBO & & $(\mathrm{n}=110)$ & 4 & 52.4 & 110.4 \\
\hline \multirow{3}{*}{ Tanaka et al., 2012 [45] } & \multirow{3}{*}{ GO-FORTH } & \multirow{3}{*}{ RA } & GLM+MTX & $50 \mathrm{mg}, \mathrm{wk}: 0,4,8,12,16,20,24$ & $(n=89)$ & 6 & 50.4 & 105.6 \\
\hline & & & GLM+MTX & $100 \mathrm{mg}$, wk: $0,4,8,12,16,20,24$ & $(n=90)$ & 6 & 50.0 & 97.2 \\
\hline & & & $\mathrm{PBO}+\mathrm{MTX}$ & & $(n=90)$ & 6 & 51.1 & 104.4 \\
\hline \multirow{5}{*}{ Van de Putte et al., 2004 [85] } & & \multirow{5}{*}{ RA } & $\mathrm{ADA}$ & $20 \mathrm{mg}$ eow & $(n=106)$ & 6.5 & 53.1 & 111.6 \\
\hline & & & $\mathrm{ADA}$ & 20 mg weekly & $(\mathrm{n}=112)$ & 6.5 & 54.4 & 135.6 \\
\hline & & & $\mathrm{ADA}$ & $40 \mathrm{mg}$ eow & $(\mathrm{n}=113)$ & 6.5 & 52.7 & 127.2 \\
\hline & & & $\mathrm{ADA}$ & 40 mg weekly & $(n=103)$ & 6.5 & 51.8 & 142.8 \\
\hline & & & PBO & & $(\mathrm{n}=110)$ & 6.5 & 53.5 & 139.2 \\
\hline \multirow{4}{*}{ Van de Putte et al., 2003 [88] } & & \multirow{4}{*}{ RA } & $\mathrm{ADA}$ & 20 mg weekly & $(n=72)$ & 3 & 53.7 & 10.4 \\
\hline & & & $\mathrm{ADA}$ & 40 mg weekly & $(n=70)$ & 3 & 52.6 & 10.0 \\
\hline & & & $\mathrm{ADA}$ & 80 mg weekly & $(n=72)$ & 3 & 53.2 & 10.1 \\
\hline & & & PBO & & $(n=70)$ & 3 & 50.2 & 9.4 \\
\hline \multirow{2}{*}{ Van den Bosch et al., 2002 [94] } & & \multirow{2}{*}{ AS } & IFX & $5 \mathrm{mg} / \mathrm{kg}, \mathrm{wk}: 0,2,6$ & $(n=20)$ & 3 & $46.0 *$ & $78.0^{*}$ \\
\hline & & & PBO & & $(n=20)$ & 3 & $47.5^{*}$ & $96.0 *$ \\
\hline \multirow{2}{*}{ Van der Heijde et al., 2007 [67] } & \multirow{2}{*}{ TEMPO } & \multirow{2}{*}{ RA } & ETA+MTX & $25 \mathrm{mg} / 2 \mathrm{w}$ & $(n=231)$ & 36 & 52.5 & 6.8 \\
\hline & & & MTX & & $(\mathrm{n}=228)$ & 36 & 53.0 & 6.8 \\
\hline \multirow{3}{*}{ Van der Heijde et al., 2006 [71] } & & \multirow{3}{*}{ AS } & ETA+DMARDs & $50 \mathrm{mg} /$ once weekly & $(n=155)$ & 3 & 41.5 & 108.0 \\
\hline & & & ETA+DMARDs & $25 \mathrm{mg} /$ twice weekly & $(n=150)$ & 3 & 39.8 & 120.0 \\
\hline & & & PBO+DMARDs & & $(n=51)$ & 3 & 40.1 & 102.0 \\
\hline \multirow{2}{*}{ Van der Heijde et al., 2006 [72] } & \multirow{2}{*}{ ATLAS } & \multirow{2}{*}{ AS } & ADA+DMARDs & $40 \mathrm{mg} / 2 \mathrm{wk}$ & $(n=208)$ & 6 & 41.7 & 11.3 \\
\hline & & & PBO+DMARDs & & $(\mathrm{n}=107)$ & 6 & 43.4 & 10.0 \\
\hline \multirow{2}{*}{ Van der Heijde et al., 2005 [79] } & \multirow{2}{*}{ ASSERT } & \multirow{2}{*}{ AS } & IFX & $5 \mathrm{mg} / \mathrm{kg}, \mathrm{wk}: 0,2,6,12,18$ & $(n=201)$ & 6 & $40.0^{*}$ & $92.4^{*}$ \\
\hline & & & $\mathrm{PBO}$ & & $(\mathrm{n}=78)$ & 6 & $41.0 *$ & $158.4^{*}$ \\
\hline \multirow{2}{*}{ Van Vollenhoven et al., 2012 [38] } & \multirow{2}{*}{ ORAL standard } & \multirow{2}{*}{ RA } & $\mathrm{ADA}+\mathrm{MTX}$ & $40 \mathrm{mg} / 2 \mathrm{wk}$ & $(n=204)$ & 3 & 52.5 & 97.2 \\
\hline & & & $\mathrm{PBO}+\mathrm{MTX}$ & & $(n=108)$ & 3 & 53.7 & 79.5 \\
\hline \multirow{2}{*}{ Van Vollenhoven et al., 2011 [48] } & \multirow{2}{*}{ AUGUST II } & \multirow{2}{*}{ RA } & $\mathrm{ADA}+\mathrm{MTX}$ & $40 \mathrm{mg} / 2 \mathrm{wk}$ & $(n=79)$ & 9.5 & 53.0 & 105.6 \\
\hline & & & $\mathrm{PBO}+\mathrm{MTX}$ & & $(n=76)$ & 9.5 & 54.0 & 100.8 \\
\hline \multirow{2}{*}{ Weinblatt et al., 2013 [42] } & & & GLM+MTX & $2 \mathrm{mg} / \mathrm{kg}$, wk: 0,4 and every $8 \mathrm{wk}$ & $(n=395)$ & 4 & 51.9 & 82.8 \\
\hline & GO-FURTHER & RA & $\mathrm{PBO}+\mathrm{MTX}$ & & $(n=197)$ & 4 & 51.4 & 84.0 \\
\hline Woinhlatt ot ol 2012 & PEAIICTIC & PA & CTP & $400 \mathrm{mg} / \mathrm{wk}: 0,2,4$ then $200 \mathrm{mg} / 2 \mathrm{wk}$ & $(\mathrm{n}=851)$ & 3 & 55.4 & 103.2 \\
\hline weinblatt et al., 2012 [37] & REALISIIC & KA & $\mathrm{PBO}$ & & $(\mathrm{n}=212)$ & 3 & 53.9 & 106.8 \\
\hline & & & $\mathrm{ADA}+\mathrm{MTX}$ & $20 \mathrm{mg} / 2 \mathrm{wk}$ & $(n=69)$ & 6 & 53.5 & 157.2 \\
\hline Weinblatt et al., 2003 [91] & ARMADA & RA & $\mathrm{ADA}+\mathrm{MTX}$ & $40 \mathrm{mg} / 2 \mathrm{wk}$ & $(n=67)$ & 6 & 57.2 & 146.4 \\
\hline & & & $\mathrm{ADA}+\mathrm{MTX}$ & $80 \mathrm{mg} / 2 \mathrm{wk}$ & $(n=73)$ & 6 & 55.5 & 153.6 \\
\hline
\end{tabular}




\begin{tabular}{|c|c|c|c|c|c|c|c|}
\hline & & $\mathrm{PBO}+\mathrm{MTX}$ & & $(n=62)$ & 6 & 56.0 & 133.2 \\
\hline \multirow{2}{*}{ Weinblatt et al., 1999 [98] } & \multirow{2}{*}{ RA } & ETA+MTX & $25 \mathrm{mg} /$ twice wk & $(\mathrm{n}=59)$ & 6 & 48 & 156 \\
\hline & & $\mathrm{PBO}+\mathrm{MTX}$ & & $(n=30)$ & 6 & 53 & 156 \\
\hline \multirow{2}{*}{ Weisman et al., 2007 [68] } & \multirow{2}{*}{ RA } & ETA+DMARDs & $25 \mathrm{mg} /$ twice wk & $(n=266)$ & 4 & $60.6^{*}$ & $121.2^{*}$ \\
\hline & & PBO+DMARDs & & $(n=269)$ & 4 & $59.3 *$ & $112.8^{*}$ \\
\hline \multirow{3}{*}{ Westhovens et al., 2006 [73] } & \multirow{3}{*}{ RA } & IFX+MTX & $3 \mathrm{mg} / \mathrm{kg}, \mathrm{wk}: 0,2,6,14$ & $(n=360)$ & 5.5 & $53.0^{*}$ & $93.6^{*}$ \\
\hline & & IFX+MTX & $10 \mathrm{mg} / \mathrm{kg}, \mathrm{wk}: 0,2,6,14$ & $(n=361)$ & 5.5 & $52.0 *$ & $75.6^{*}$ \\
\hline & & $\mathrm{PBO}+\mathrm{MTX}$ & & $(n=363)$ & 5.5 & $52.0 *$ & $100.8 *$ \\
\hline \multirow{2}{*}{ Zhang et al., 2006 [100] } & \multirow{2}{*}{ RA } & IFX+MTX & $3 \mathrm{mg} / \mathrm{kg}$, wk: $0,2,6,14$ & $(n=87)$ & 4.5 & 47.9 & 85.6 \\
\hline & & $\mathrm{PBO}+\mathrm{MTX}$ & & $(n=86)$ & 4.5 & 48.9 & 96.0 \\
\hline \multirow{7}{*}{ Zhou et al., 2007 [70] } & \multirow{7}{*}{ RA } & GLM+DMARDs & $0.1 \mathrm{mg} / \mathrm{kg}$ & $(n=3)$ & 4 & 48.0 & NR \\
\hline & & GLM+DMARDs & $0.3 \mathrm{mg} / \mathrm{kg}$ & $(n=3)$ & 4 & 44.0 & NR \\
\hline & & GLM+DMARDs & $1 \mathrm{mg} / \mathrm{kg}$ & $(n=5)$ & 4 & 43.0 & NR \\
\hline & & GLM+DMARDs & $3 \mathrm{mg} / \mathrm{kg}$ & $(n=5)$ & 4 & 67.0 & NR \\
\hline & & GLM+DMARDs & $6 \mathrm{mg} / \mathrm{kg}$ & $(n=5)$ & 4 & 50.0 & NR \\
\hline & & GLM+DMARDs & $10 \mathrm{mg} / \mathrm{kg}$ & $(n=5)$ & 4 & 46.0 & NR \\
\hline & & PBO+DMARDs & & $(\mathrm{n}=10)$ & 4 & 60.0 & NR \\
\hline
\end{tabular}

Abbreviations. ADA: adalimubab; AS: ankylosing spondylitis; CTP: certolizumab pegol; DMARDs: disease-modifying anti-rheumatic drugs; eow: every other week; ETA: etanercept; GLM: golimubab; IFX: infliximab; MTX: methotrexate; NR: not reported; PsA: psoriatic arthritis; PBO: placebo; RA: rheumatoid arthritis; wk: week.

Footnote. Mean values are given for äge of patients"and disease duration,"or median values when indicated with an asterisk. 
Table 2. Meta-analysis results.

\begin{tabular}{|c|c|c|c|c|c|c|c|c|c|c|}
\hline & \multirow[b]{2}{*}{ No. of studies } & \multicolumn{2}{|c|}{ Fixed-effects model } & \multicolumn{2}{|c|}{ Random-effects model } & \multicolumn{3}{|c|}{ Tests of homogeneity } & \multicolumn{2}{|c|}{ Tests of publication bias } \\
\hline & & OR & $(95 \% \mathrm{CI})$ & OR & $(95 \% \mathrm{CI})$ & $Q$ value (d.f.) & P-value & $\mathrm{I}^{2}$ & Begg's p-value & Egger's p-value \\
\hline \multicolumn{11}{|l|}{ Serious Infections } \\
\hline - All RCTs & 58 & 1.41 & $(1.16,1.73)$ & 1.25 & $(1.01,1.55)$ & $48.48(57)$ & 0.78 & $0 \%$ & 0.06 & 0.09 \\
\hline - RCT high-dose arms* & 58 & 1.46 & $(1.19,1.79)$ & 1.36 & $(1.09,1.69)$ & $45.68(57)$ & 0.86 & $0 \%$ & 0.25 & 0.16 \\
\hline - OLE studies & 6 & 1.33 & $(0.77,2.29)$ & 1.19 & $(0.68,2.07)$ & $4.39(5)$ & 0.49 & $0 \%$ & 0.45 & 0.22 \\
\hline \multicolumn{11}{|l|}{ Tuberculosis } \\
\hline - All RCTs & 19 & 3.53 & $(1.58,7.85)$ & 3.29 & $(1.48,7.33)$ & $0.62(18)$ & 0.99 & $0 \%$ & 0.94 & 0.05 \\
\hline - RCT high-dose arms* & 19 & 3.32 & $(1.54,7.15)$ & 3.23 & $(1.50,6.98)$ & $0.48(18)$ & 0.99 & $0 \%$ & 0.03 & 0.07 \\
\hline \multicolumn{11}{|l|}{ Opportunistic Infections } \\
\hline - All RCTs & 6 & 0.94 & $(0.33,2.64)$ & 0.81 & $(0.23,2.87)$ & $3.32(5)$ & 0.65 & $0 \%$ & 0.13 & 0.12 \\
\hline - RCT high-dose arms* & 6 & 0.98 & $(0.35,2.73)$ & 0.87 & $(0.25,3.00)$ & $3.59(5)$ & 0.61 & $0 \%$ & 0.02 & 0.16 \\
\hline \multicolumn{11}{|l|}{ Any Infection } \\
\hline - All RCTs & 37 & 1.20 & $(1.10,1.30)$ & 1.20 & $(1.06,1.36)$ & $66.45(36)$ & $<0.01$ & $46 \%$ & 0.95 & 0.75 \\
\hline - RCT high-dose arms* & 37 & 1.21 & $(1.11,1.32)$ & 1.22 & $(1.07,1.39)$ & $67.44(36)$ & $<0.01$ & $47 \%$ & 0.80 & 0.74 \\
\hline - OLE studies & 6 & 1.69 & $(1.31,2.18)$ & 1.56 & $(1.05,2.33)$ & $9.11(5)$ & 0.10 & $45 \%$ & 0.26 & 0.61 \\
\hline
\end{tabular}


RCTs: randomized controlled trials; OLE: open label extension; OR: odds ratio; CI: confidence interval; d.f.: degrees of freedom.

*analysis using (from the multi-arm trials) only the data referring to the intervention arm exposed to the highest dose. 
Table 3. Summary of findings.

Population: Adult patients with rheumatologic disease (rheumatoid arthritis, psoriatic arthritis, or ankylosing spondylitis)

Intervention: Anti-TNF drugs (adalimumab, certolizumab, etanercept, golimumab, or infliximab)

Comparison: Placebo or no treatment

Follow-up: $1-36$ months (8 months per patient, on average)

\begin{tabular}{|c|c|c|c|}
\hline & \multicolumn{2}{|c|}{ Illustrative comparative risks ( $95 \% \mathrm{CI}$ ) } & \\
\hline & Assumed risk & Corresponding risk & \\
\hline & PBO or no treatment & Anti-TNF drugs & \\
\hline Serious Infections & 20 per 1000 & $\begin{array}{l}28 \text { per } 1000 \\
(23 \text { to } 34)\end{array}$ & $\begin{array}{l}\text { Relative effect ( } 95 \% \text { CI): OR, } 1.41(1.16,1.73) \\
\text { No. of participants: } 20,796 \\
\text { No. of RCTs: } 58 \\
\text { Quality of the evidence (GRADE): } \oplus \oplus \oplus \Theta \text { (Moderate) }\end{array}$ \\
\hline Opportunistic Infections & 3 per 1000 & $\begin{array}{l}3 \text { per } 1000 \\
(1 \text { to } 8)\end{array}$ & $\begin{array}{l}\text { Relative effect }(95 \% \text { CI): OR, } 0.94(0.33,2.64) \\
\text { No. of participants: } 3,886 \\
\text { No. of RCTs: } 6 \\
\text { Quality of the evidence (GRADE): } \oplus \oplus \Theta \Theta \text { (Low) }\end{array}$ \\
\hline Any Infection & 285 per 1000 & $\begin{array}{c}324 \text { per } 1000 \\
(305 \text { to } 341)\end{array}$ & $\begin{array}{l}\text { Relative effect }(95 \% \text { CI): OR, } 1.20(1.10,1.30) \\
\text { No. of participants: } 12,796 \\
\text { No. of RCTs: } 37 \\
\text { Quality of the evidence (GRADE): } \oplus \oplus \oplus \Theta \text { (Moderate) }\end{array}$ \\
\hline
\end{tabular}

Footnotes:

(i) the basis for the assumed risk is the overall event occurrence across RCT control groups,

(ii) the corresponding risk is based on the assumed risk in the comparison group and the relative effect of the intervention,

(iii) the relative effect and its $95 \% \mathrm{CI}$ come from a fixed-effects meta-analytic model,

(iv) a corresponding risk could not be estimated for Tuberculosis, because no event was reported in the control groups,

(v) the overall quality of the synthesized evidence is "moderate" for the following reasons: Data was derived from RCTs (randomized study design is considered the gold standard for assessing drugs); the meta-analytic effect estimates are precise (except for opportunistic infections); the results are consistent (heterogeneity was low or moderate across studies); and all the RCTs included in meta-analysis are characterized by high or unclear RoB in several important quality domains, such as allocation concealment and incomplete outcome data (a fact that downgrades the quality of evidence). A moderate quality of evidence means that "we are moderately confident in the effect estimate. The true effect is likely to be close to the estimate of the effect, but there is a possibility that it is substantially different". (vi) explanations for Summary of findings Tables can be found at: www.thecochranelibrary.com/view/0/SummaryFindings.html

Abbreviations. CI: confidence interval; OR: odds ratio; PBO: placebo; RoB: risk of bias. 